\title{
Facile Construction of Supramolecular Organic Framework using Naphthyl Viologen Guests and CB[8] Host via CT complexation
}

Kanagaraj Madasamy, ${ }^{1,2}$ David Velayutham, ${ }^{1,2}$ Murugavel Kathiresan*1,2

${ }^{1}$ Electroorganic Division, CSIR-Central Electrochemical Research Institute, Karaikudi, 630003, TamilNadu, India.

2 Academy of Scientific and Innovative Research (AcSIR), CSIR-Central Electrochemical Research Institute, Karaikudi, 630003, TamilNadu, India.

E-mail: kathiresan@cecri.res.in 


\section{Supporting Information}

\section{Synthetic Procedures}

\section{Synthesis of compound 1}

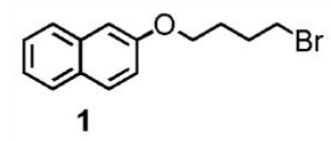

Reported procedure was followed to obtain $1(83 \%){ }^{1}$

${ }^{1} \mathrm{H}$ NMR (500 MHz, DMSO- $\left.d_{6}\right): \delta$, ppm 7.88-7.82 (m, 3H), $7.55(\mathrm{t}, 1 \mathrm{H}), 7.45(\mathrm{t}, 1 \mathrm{H}), 7.26-7.22$

(m, 2H), $4.18(\mathrm{t}, 2 \mathrm{H}), 3.59(\mathrm{t}, 2 \mathrm{H}), 2.22-2.17(\mathrm{~m}, 2 \mathrm{H}), 2.11-2.06(\mathrm{~m}, 2 \mathrm{H})$.

${ }^{13} \mathrm{C}$ NMR (125 MHz, DMSO- $\left.d_{6}\right): \delta$, ppm 156.9, 134.6, 129.5, 129.0, 127.7, 126.8, 126.5, 123.7, $118.9,106.6,66.9,33.6,29.6,27.9$.

Anal. Calcd for $\mathrm{C}_{14} \mathrm{H}_{15} \mathrm{BrO}$ : C, 60.23; H, 5.42. Found C, 60.04; H, 5.26.

\section{Synthesis of compound 2}

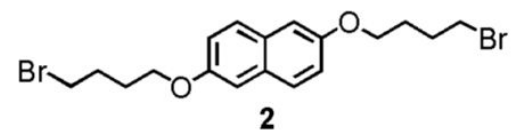

Reported procedure was followed to obtain $2(75 \%){ }^{2}$

${ }^{1} \mathrm{H}$ NMR (500 MHz, DMSO-d $)$ ): $\delta$, ppm $7.62(\mathrm{~d}, 2 \mathrm{H}), 7.10-7.08(\mathrm{~m}, 4 \mathrm{H}), 4.09(\mathrm{t}, 4 \mathrm{H}), 3.51(\mathrm{t}$, 4H), 2.13-2.10 (m, 4H), 2.02-1.99 (m, 4H).

${ }^{13} \mathrm{C}$ NMR (125 MHz, DMSO- $\left.d_{6}\right): \delta$, ppm 155.4, 129.8, 128.2, 119.2, 107.0, 67.0, 33.6, 29.6, 28.0.

Anal. Calcd for $\mathrm{C}_{18} \mathrm{H}_{22} \mathrm{Br}_{2} \mathrm{O}_{2}$ : C, 50.26; H, 5.15. Found C, 49.98; H, 5.01. 


\section{Synthesis of compound 3}

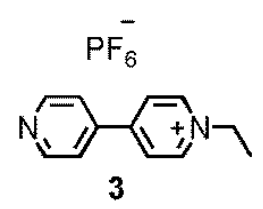

Reported procedure was followed to obtain $3(84 \%){ }^{3}$

${ }^{1} \mathrm{H}$ NMR (500 MHz, DMSO- $\left.d_{6}\right): \delta$, ppm $8.87(\mathrm{~d}, J=5.0 \mathrm{~Hz}, 2 \mathrm{H}), 8.81(\mathrm{~d}, J=10.0 \mathrm{~Hz}, 2 \mathrm{H}), 8.33$

$(\mathrm{d}, J=5.0 \mathrm{~Hz}, 2 \mathrm{H}), 7.81(\mathrm{~d}, J=5.0 \mathrm{~Hz}, 2 \mathrm{H}), 4.63(\mathrm{q}, J=5.0 \mathrm{~Hz}, 2 \mathrm{H}), 1.65(\mathrm{t}, J=15.0 \mathrm{~Hz}, 3 \mathrm{H})$.

${ }^{13} \mathrm{C}$ NMR (125 MHz, DMSO- $\left.d_{6}\right): \delta$, ppm 154.7, 151.9, 145.5, 142.1, 57.8, 16.4.

Anal.Calcd for $\mathrm{C}_{14} \mathrm{H}_{21} \mathrm{~F}_{6} \mathrm{~N}_{2} \mathrm{P}: \mathrm{C}, 46.41 ; \mathrm{H}, 5.84 ; \mathrm{N}, 7.73$. Found C, 46.33; H, 5.50; N, 7.88.

\section{Synthesis of compound Np-Vio-Np}

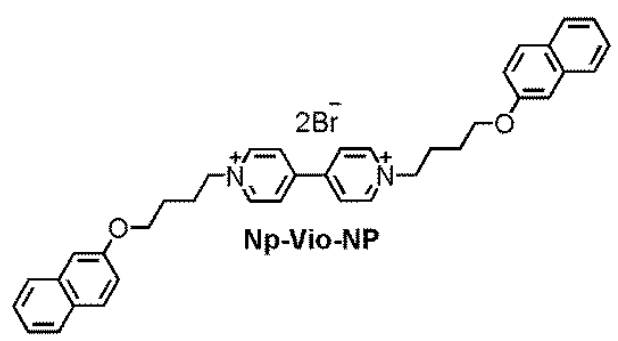

4,4'-bipyridine (0.1 g, $0.64 \mathrm{mmol})$ and compound $1(0.9 \mathrm{~g}, 3.20 \mathrm{mmol})$ were dissolved in $25 \mathrm{ml}$ $\mathrm{CH}_{3} \mathrm{CN}$ and stirred at $80{ }^{\circ} \mathrm{C}$ for $4 \mathrm{~d}$. The progress of the reaction was monitored by TLC [With time, the amount of yellow precipitate has gradually increased in solution indicating the conversion]. After completion of the reaction, the solvent was removed under reduced pressure and the resultant yellow precipitate was washed with excess of acetonitrile. Finally the washed yellow precipitate was dried under vacuum to afford the Np-Vio-NP $(0.37 \mathrm{~g}, 80 \%)$.

${ }^{1} \mathrm{H}$ NMR (500 MHz, DMSO-d $)$ ): $\delta$, ppm $9.46(\mathrm{~d}, J=10.0 \mathrm{~Hz}, 4 \mathrm{H}), 8.79(\mathrm{~d}, J=10.0 \mathrm{~Hz}, 4 \mathrm{H})$, 7.83-7.77 (m, 6H), 7.47-7.43 (m, 2H), 7.35-7.31 (m, 4H), $7.14(\mathrm{dd}, J=5.0 \mathrm{~Hz}, 2 \mathrm{H}), 4.82(\mathrm{t}, J=$ $15.0 \mathrm{~Hz}, 4 \mathrm{H}), 4.16(\mathrm{t}, J=15.0 \mathrm{~Hz}, 4 \mathrm{H}), 2.26-2.19(\mathrm{~m}, 4 \mathrm{H}), 1.90-1.84(\mathrm{~m}, 4 \mathrm{H})$. 
${ }^{13} \mathrm{C}$ NMR (125 MHz, DMSO- $\left.d_{6}\right): \delta$, ppm 156.2, 148.5, 145.8, 134.2, 129.3, 128.4, 127.5, 126.6, $126.5,126.4,123.6,118.6,106.7,66.7,60.6,27.7,25.2$.

Anal.Calcd for $\mathrm{C}_{38} \mathrm{H}_{38} \mathrm{Br}_{2} \mathrm{~N}_{2} \mathrm{O}_{2}$ : C, 63.88; H, 5.36; N, 3.92. Found C, 63.97; H, 5.13; N, 3.87.

ESI-MS m/z calcd for $\mathrm{C}_{38} \mathrm{H}_{38} \mathrm{Br}_{2} \mathrm{~N}_{2} \mathrm{O}_{2}[\mathrm{M}+\mathrm{Na}]^{+}$714.52; found 714.33.

\section{Synthesis of compound Vio-Np-Vio}

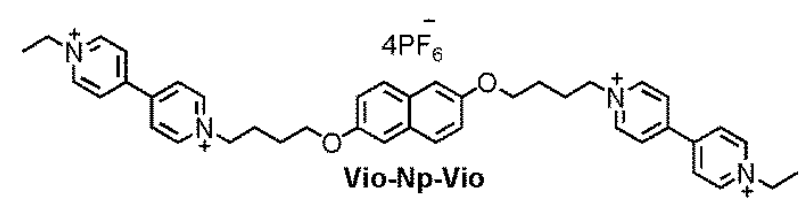

Mixture of compound $2(0.1 \mathrm{~g}, 0.23 \mathrm{mmol})$ and $3(0.38 \mathrm{~g}, 1.16 \mathrm{mmol})$ were dissolved in $25 \mathrm{ml}$ $\mathrm{CH}_{3} \mathrm{CN}$ and stirred at $80^{\circ} \mathrm{C}$ for $4 \mathrm{~d}$ (With time, brown color precipitate formed in solution). The progress of the reaction was monitored by TLC. After completion of the reaction, the solvent was removed under reduced pressure and the resultant yellow brown color solid was washed with excess of acetonitrile. Finally the brown precipitate was dried under vacuum to yield the Vio-Np-Vio $(0.37 \mathrm{~g}, 80 \%)$.

${ }^{1} \mathrm{H}$ NMR (500 MHz, $\mathrm{CD}_{3} \mathrm{CN}$ ): $\delta, \operatorname{ppm} 8.92(\mathrm{dd}, J=7.5 \mathrm{~Hz}, 8 \mathrm{H}), 8.39-8.35(\mathrm{~m}, 8 \mathrm{H}), 7.69(\mathrm{~d}, J=$ $15.0 \mathrm{~Hz}, 2 \mathrm{H}), 7.20-7.10(\mathrm{~m}, 4 \mathrm{H}), 4.76-4.65(\mathrm{~m}, 8 \mathrm{H}), 4.12(\mathrm{t}, J=15.0 \mathrm{~Hz}, 4 \mathrm{H}), 2.28-2.18(\mathrm{~m}$, $4 \mathrm{H}), 1.65(\mathrm{t}, J=15.0 \mathrm{~Hz}, 6 \mathrm{H})$.

${ }^{13} \mathrm{C}$ NMR $\left(125 \mathrm{MHz}, \mathrm{CD}_{3} \mathrm{CN}\right): \delta$, ppm 156.1, 150.8, 146.5, 146.2, 130.7, 129.0, 128.0, 128.0, $119.9,108.0,67.8,62.7,58.6,28.9,26.3,16.4$.

Anal.Calcd for $\mathrm{C}_{42} \mathrm{H}_{48} \mathrm{~F}_{24} \mathrm{~N}_{4} \mathrm{O}_{2} \mathrm{P}_{4} \cdot \mathrm{H}_{2} \mathrm{O}$ : C, 40.72; H, 4.07; N, 4.52. Found C, 40.45; H, 3.88; N, 4.46 .

ESI-MS m/z calcd for $\mathrm{C}_{42} \mathrm{H}_{48} \mathrm{~F}_{24} \mathrm{~N}_{4} \mathrm{O}_{2} \mathrm{P}_{4}[2 \mathrm{M}+\mathrm{Cu}]^{+} 1220.71$; found 1220.32 . 


\section{Synthesis of compound ETV}

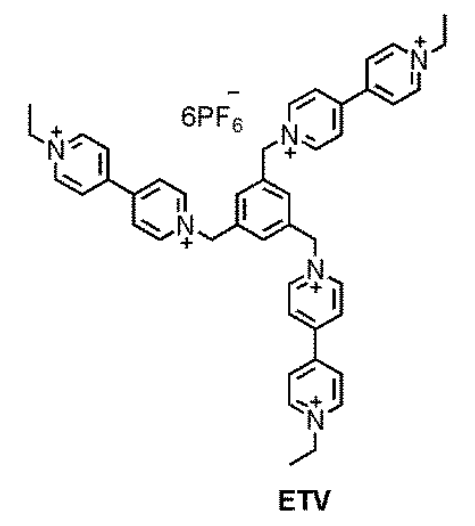

Reported procedure was followed to obtain ETV $(72 \%) .^{3}$

${ }^{1} \mathrm{H}$ NMR (500 MHz, $\left.\mathrm{CD}_{3} \mathrm{CN}\right): \delta$, ppm $8.92(\mathrm{~d}, J=10.0 \mathrm{~Hz}, 12 \mathrm{H}), 8.43-8.37$ (m, 12H), 7.67-7.52

(m, 3H), 5.83 (s, 6H), 4.67 (q, $J=10.0 \mathrm{~Hz}, 6 \mathrm{H}), 1.64$ (t, $J=10.0 \mathrm{~Hz}, 9 \mathrm{H})$.

${ }^{13} \mathrm{C}$ NMR (125 MHz, $\left.\mathrm{CD}_{3} \mathrm{CN}\right): \delta$, ppm 151.8, 150.3, 146.7, 146.3, 132.8, 132.1, 128.4, 128.3, $128.1,128.1,64.5,58.6,16.5$.

Anal. Calcd for $\mathrm{C}_{51} \mathrm{H}_{71} \mathrm{~F}_{36} \mathrm{~N}_{6} \mathrm{P}_{6} .2 \mathrm{H}_{2} \mathrm{O}: \mathrm{C}, 36.59 ; \mathrm{H}, 4.52 ; \mathrm{N}, 5.02$. Found $\mathrm{C}, 36.47 ; \mathrm{H}, 4.31 ; \mathrm{N}$, 5.15 .

ESI-MS m/z calcd for $\mathrm{C}_{45} \mathrm{H}_{48} \mathrm{~F}_{36} \mathrm{~N}_{6} \mathrm{P}_{6}[2 \mathrm{M}+\mathrm{Cu}]^{+}$1542.68; found 1542.29. 
2. Visual color changes observed during NMR titration

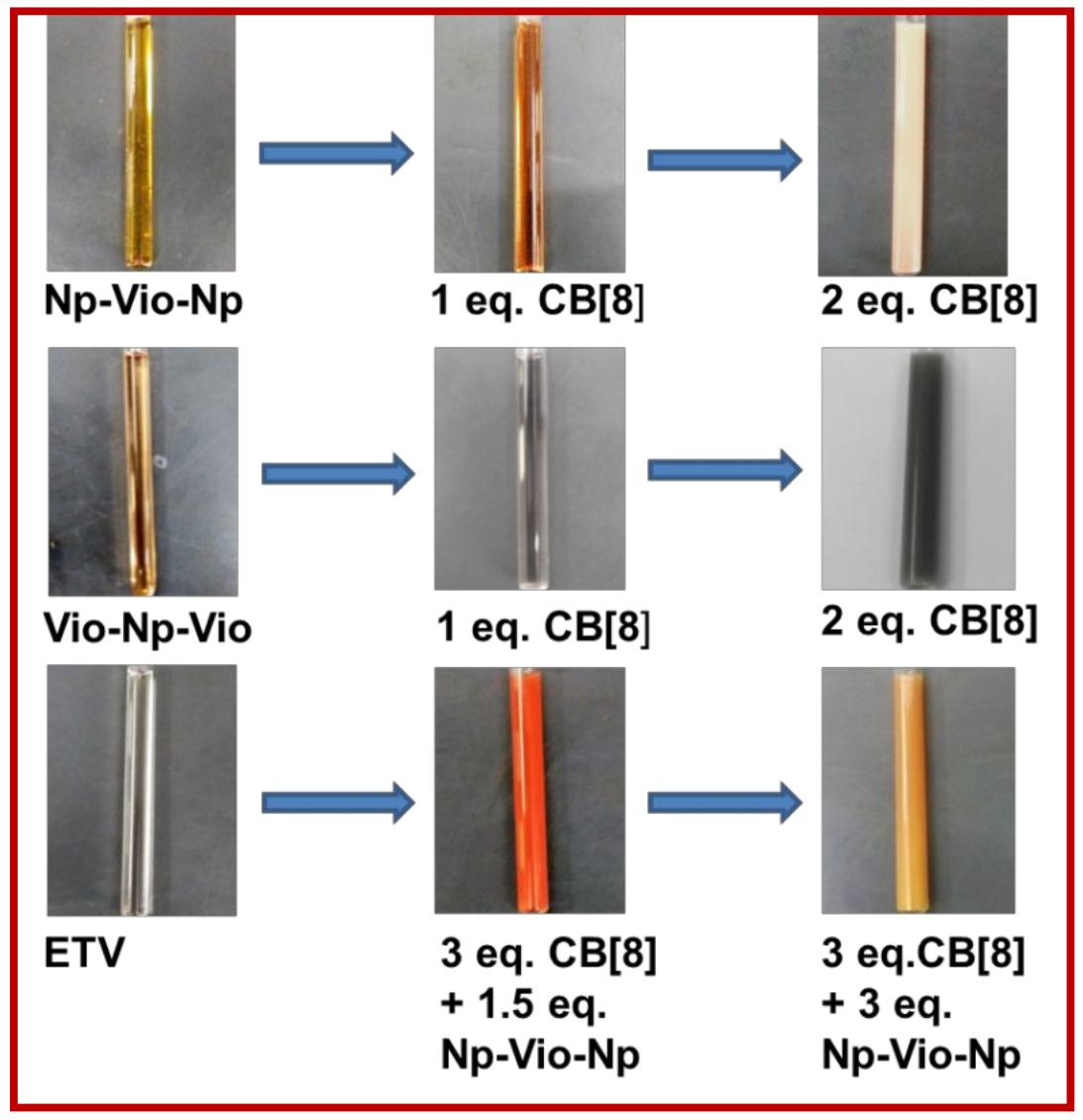

Figure S1. Photographic images show the color changes of viologen guests (Np-Vio-Np, Vio$\mathrm{Np}-\mathrm{Vio}$, and ETV) upon addition of $\mathrm{CB}[8]$ host in different concentration during NMR study in $\mathrm{D}_{2} \mathrm{O}$ at $25^{\circ} \mathrm{C}$ 


\section{Cyclic voltammetry}

The electrochemical redox behavior of viologen guest molecules (Np-Vio-Np, Vio-Np-Vio and ETV) and their inclusion behavior were monitored in the absence and presence of $\mathrm{CB}[8]$ host in water (Figure S1).
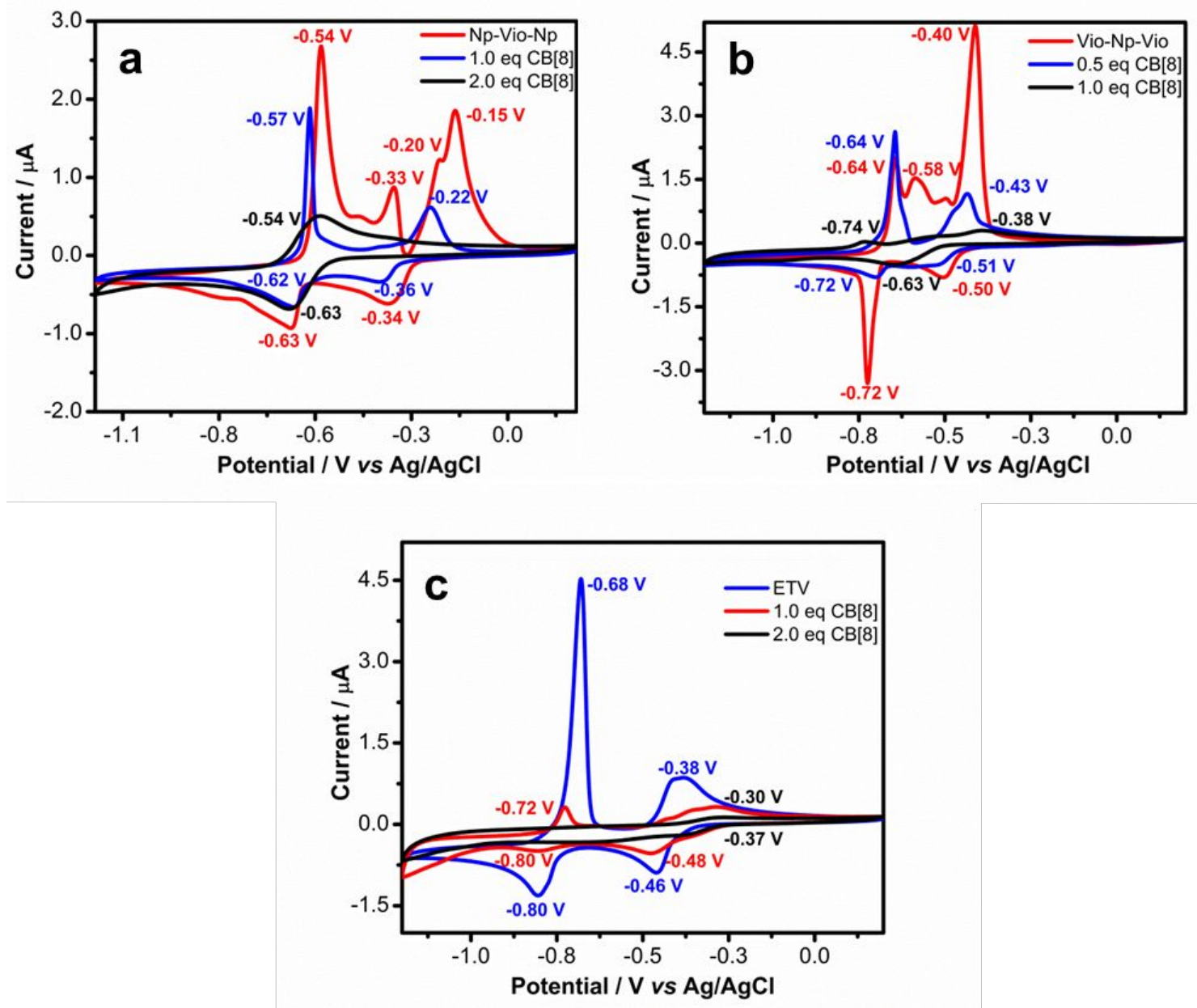

Figure S2. Cyclic voltammograms of viologen molecules: a) Np-Vio-Np; b) Vio-Np-Vio and c) ETV $(1.0 \mathrm{mM})$ in aqueous $\mathrm{KCl}(0.1 \mathrm{M})$ on glassy carbon $\left(0.07 \mathrm{~cm}^{2}\right)$ in the presence of $\mathrm{CB}[8]$ in different concentration at $V=0.05 \mathrm{~V} / \mathrm{s}, \mathrm{RT}$.

The guest molecules Vio-Np-Vio and ETV consist of viologen moiety in terminal. But in the case of Np-Vio-Np molecule it is in its center. In general, the first reduction in viologen unit is reasonably easier than the second reduction owing to the electron deficiency of the dication $\left(\mathrm{V}^{2+}\right)$ than monocation radical $\left(\mathrm{V}^{+*}\right)$ which is often known to undergo inter/intramolecular $\mathrm{CT}$ complexation or irreversible dimerisation. The first two reductions peaks appeared at the potentials of $-0.34 \mathrm{~V},-0.63 \mathrm{~V}$ for $\mathrm{Np}-\mathrm{Vio}-\mathrm{Np},-0.50 \mathrm{~V},-0.72 \mathrm{~V}$ for Vio-Np-Vio and $-0.46 \mathrm{~V}$, - 
$0.80 \mathrm{~V}$ for ETV corresponding to the conversion of $\mathrm{V}^{2+} \leftrightarrow \mathrm{V}^{+\bullet}$ and $\mathrm{V}^{+\bullet} \leftrightarrow \mathrm{V}^{0}$ respectively. Subsequent addition of $\mathrm{CB}[8]$ to the guest solution gradually suppressed the redox behavior of viologen which is ascribed to the incorporation of viologen moiety into $\mathrm{CB}$ [8] hydrophobic cavity. Moreover, unexpected CV pattern on anodic oxidation side at the potentials of - 0.33 , $0.20 \mathrm{~V}$ and $-0.15 \mathrm{~V}$ for $\mathrm{Np}-\mathrm{Vio}-\mathrm{Np},-0.58$ for Vio-Np-Vio guest molecules indicate the existence of different forms (complexed and uncomplexed radical cation) of radical cation upon addition of $\mathrm{CB}[8]$.

\section{Zeta potential}

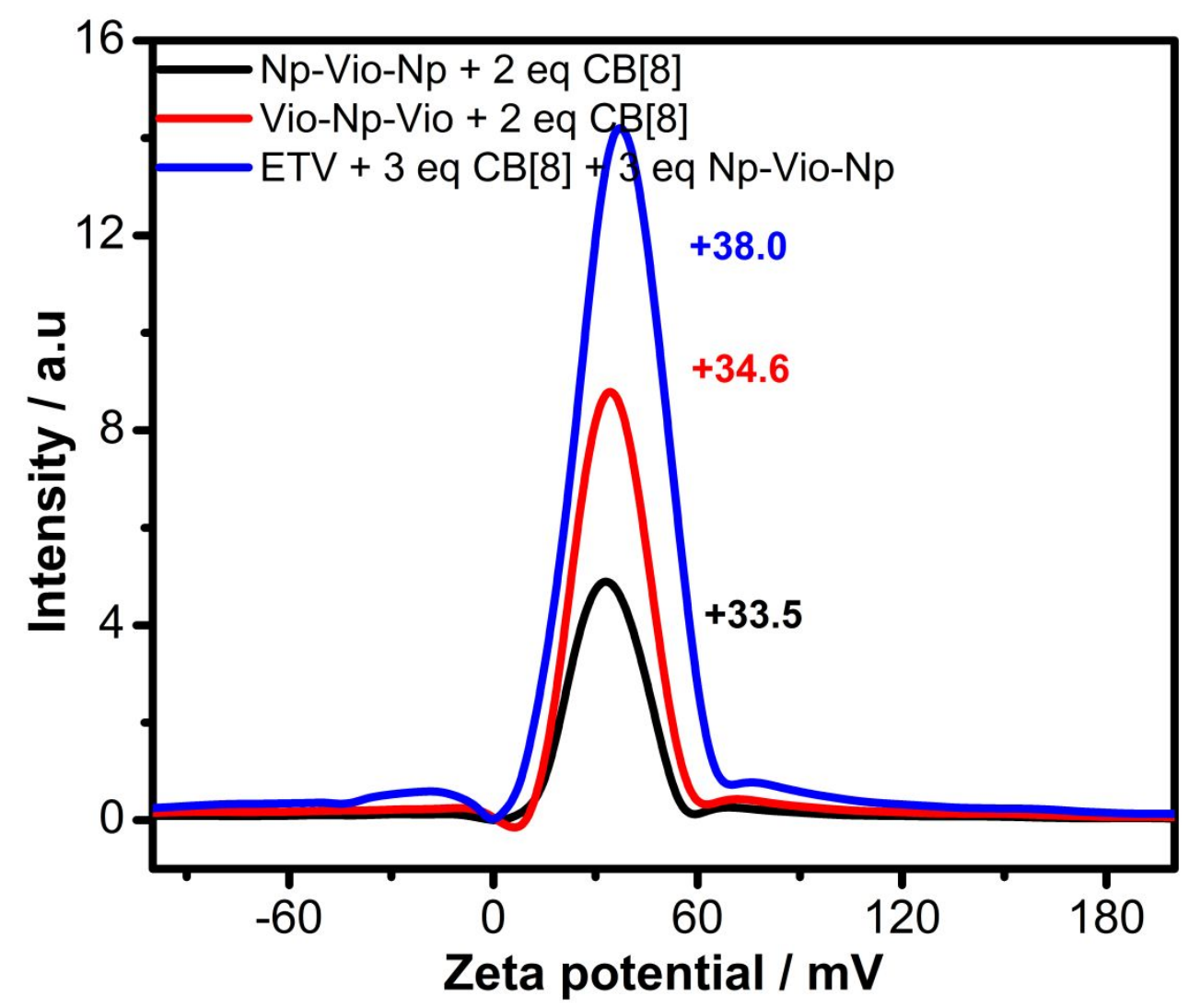

Figure S3. Zeta potential measurements of Np-Vio-Np, Vio-Np-Vio and ETV (0.70 mM) molecules in the presence of $\mathrm{CB}[8]$ in different stoichiometric ratio in $\mathrm{H}_{2} \mathrm{O}$, RT. 
5. DOSY spectra of Np-Vio-Np, Vio-Np-Vio, ETV and CB[8] and the complex at different ratio of $\mathrm{CB}[8]$

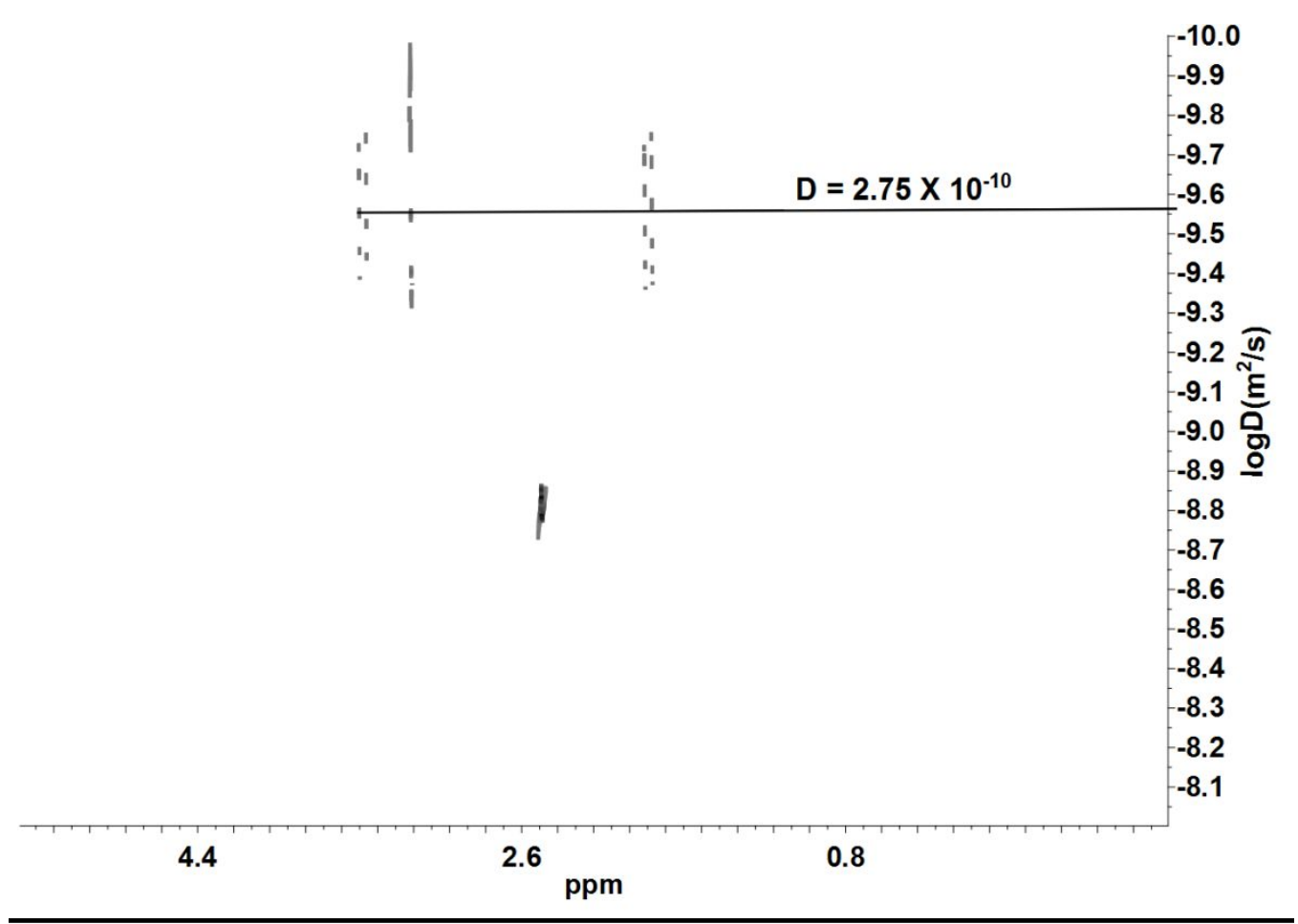

Figure S4. DOSY spectrum of $\mathbf{C B}[\mathbf{8}]$

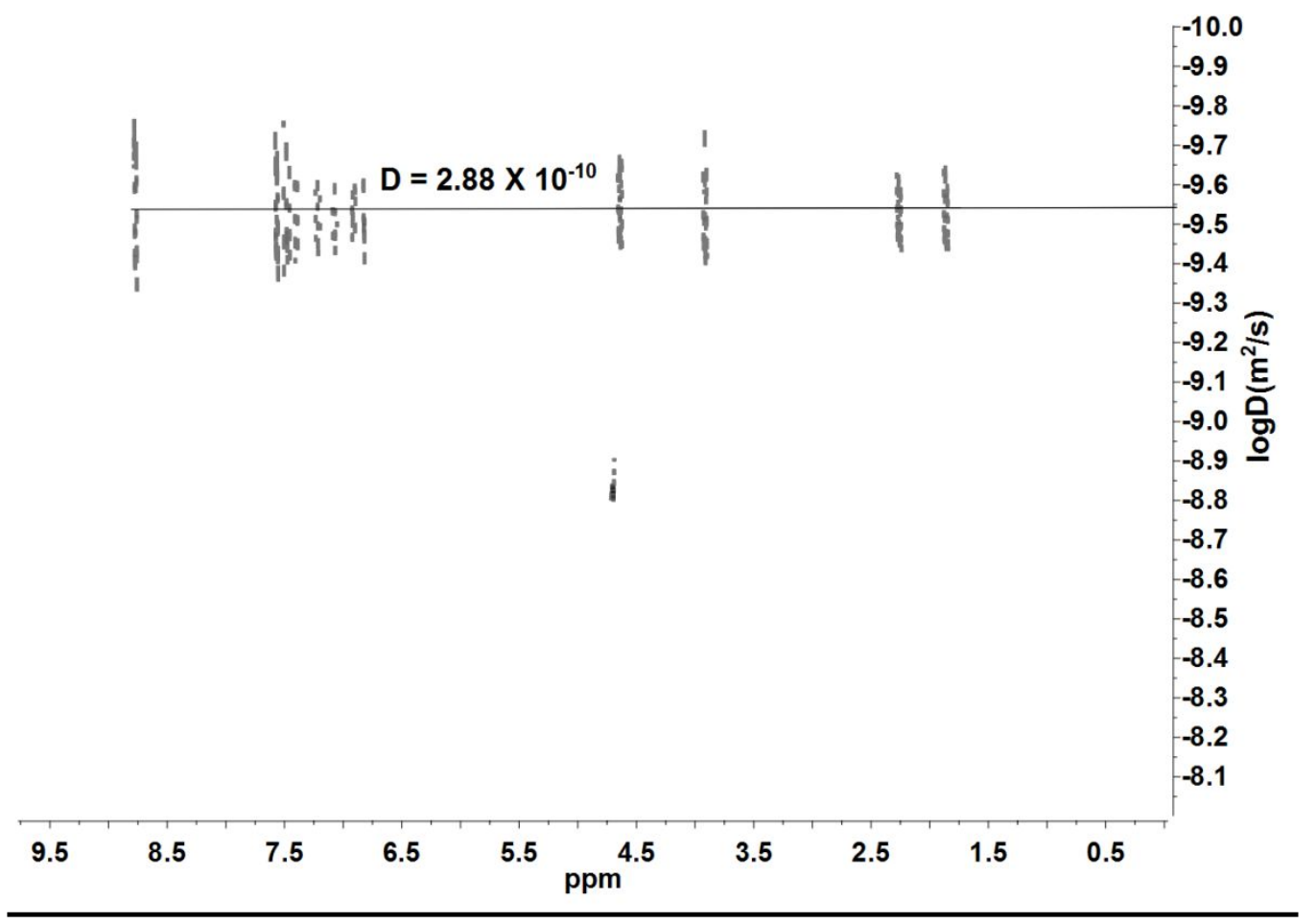

Figure S5. DOSY spectrum of Np-Vio-Np 


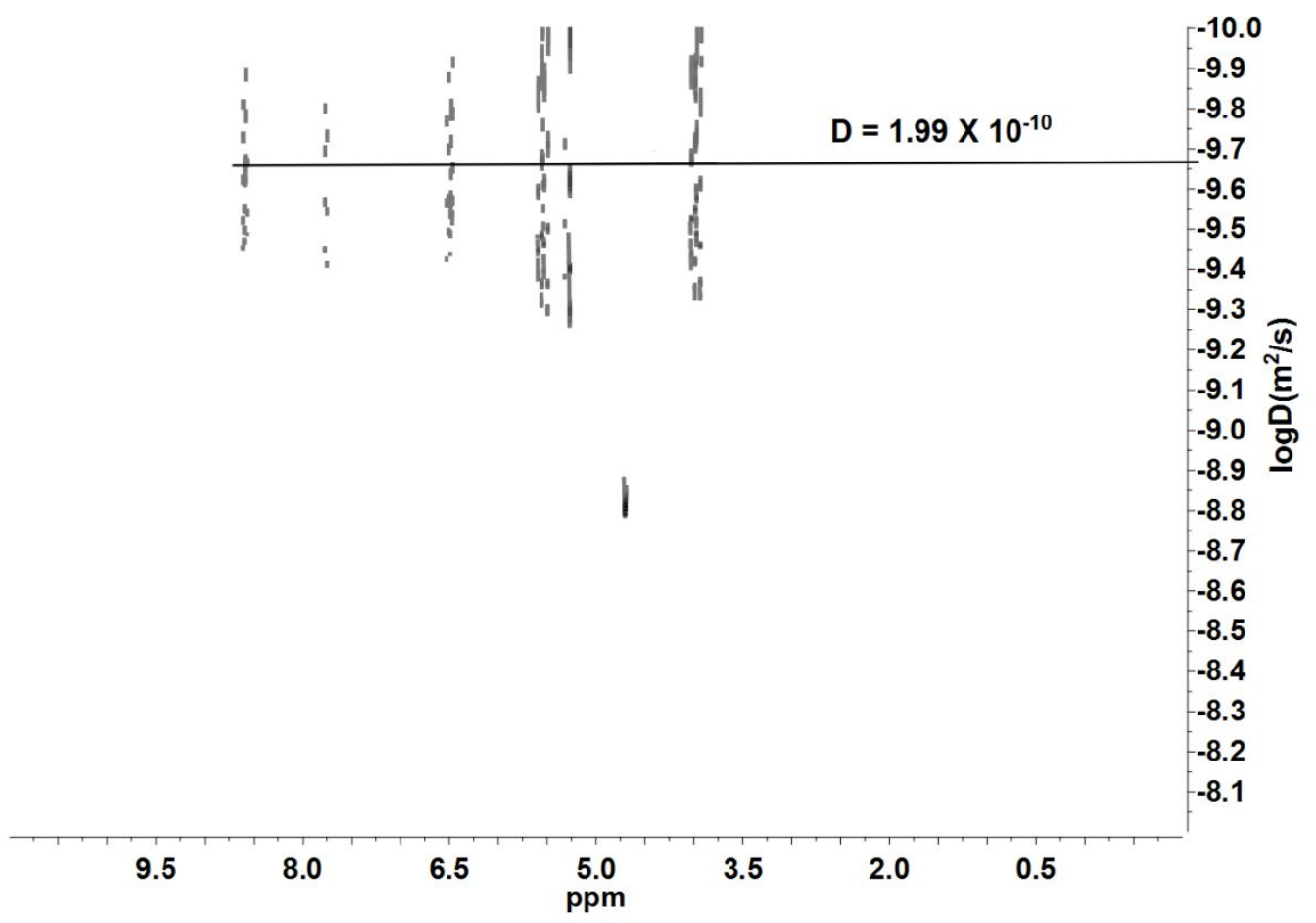

Figure S6. DOSY spectrum of Np-Vio-Np + 1.0 eq. CB[8]

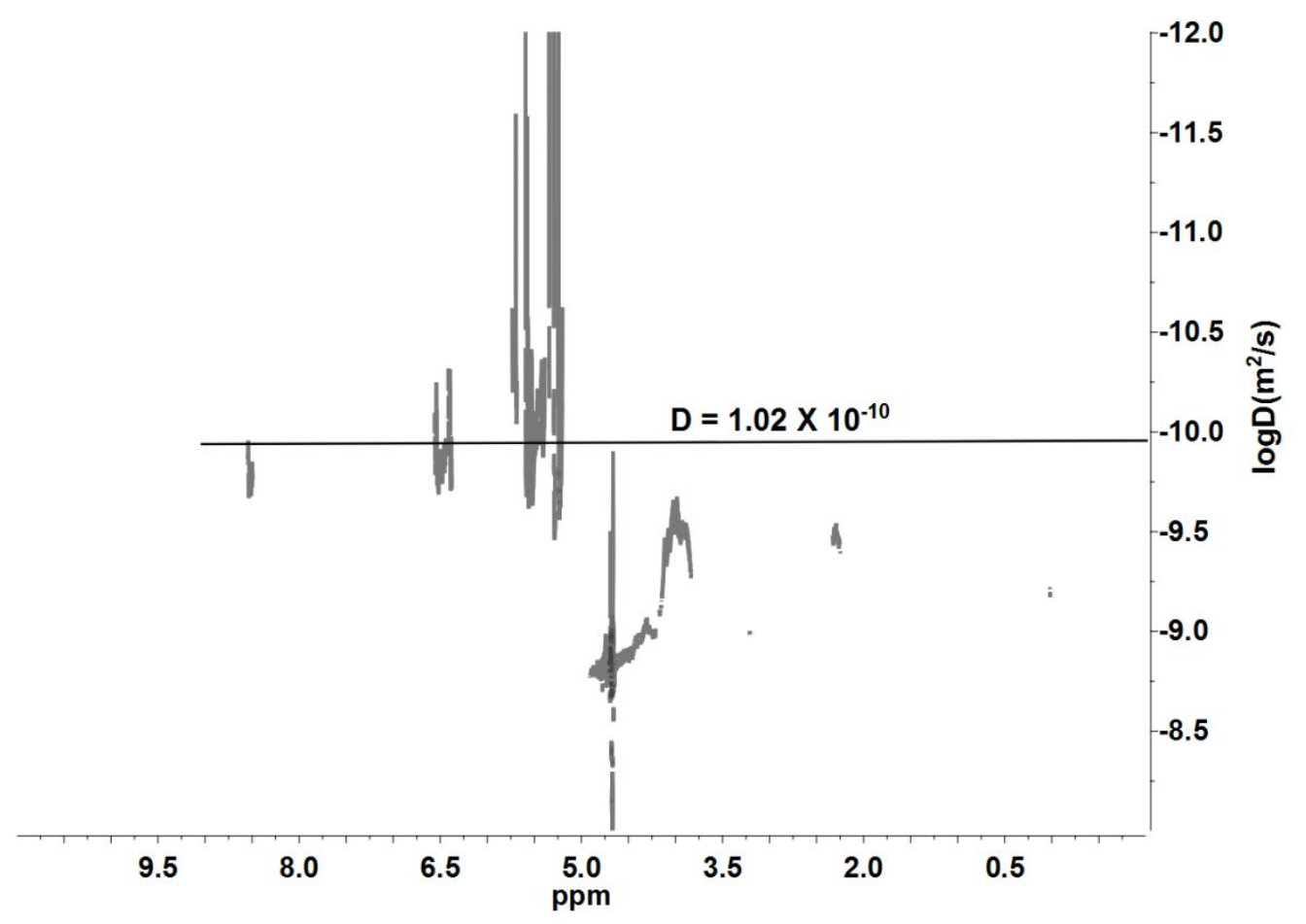

Figure S7. DOSY spectrum of Np-Vio-Np + 2.0 equiv. CB[8] 


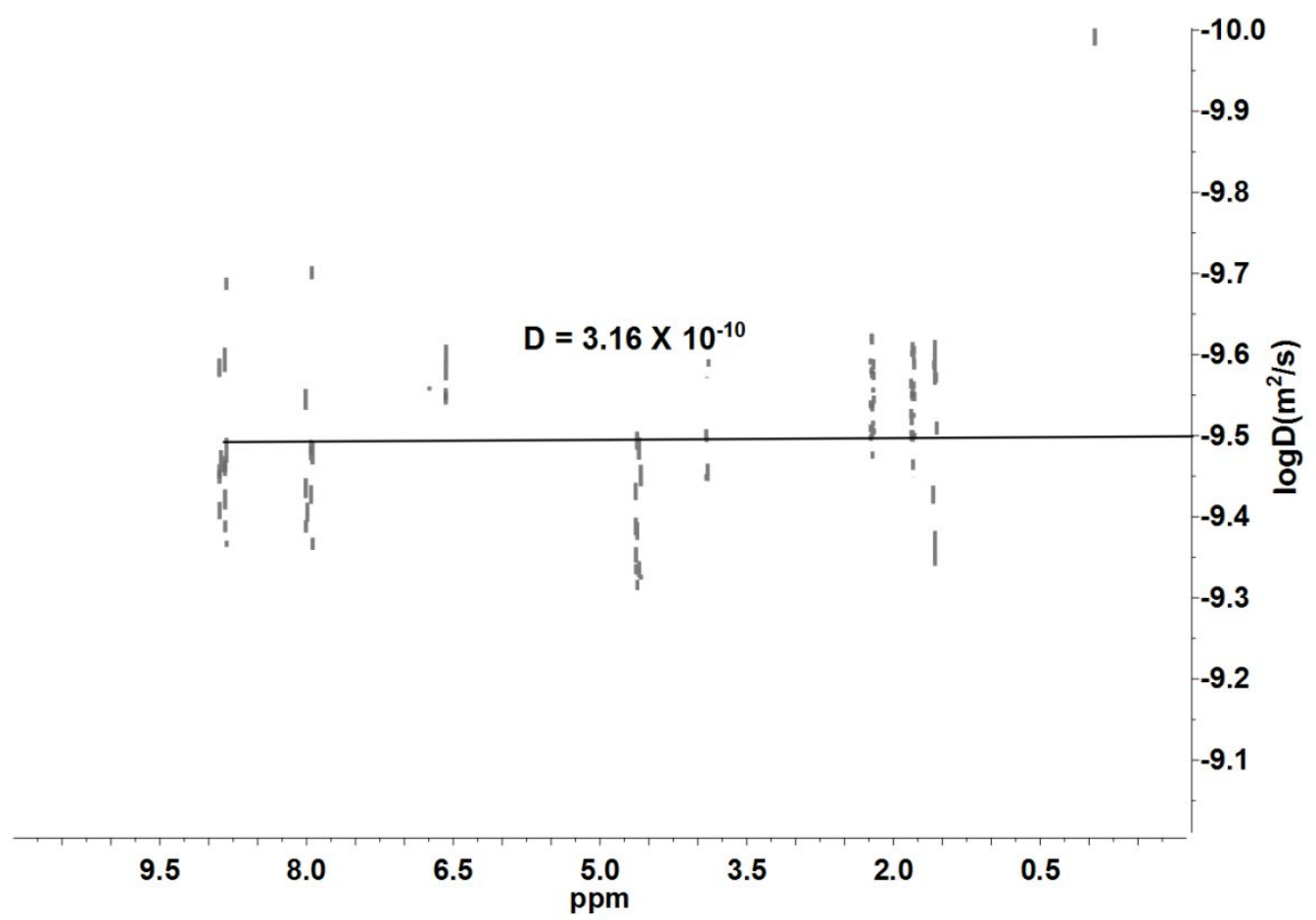

Figure S8. DOSY spectrum of Vio-Np-Vio

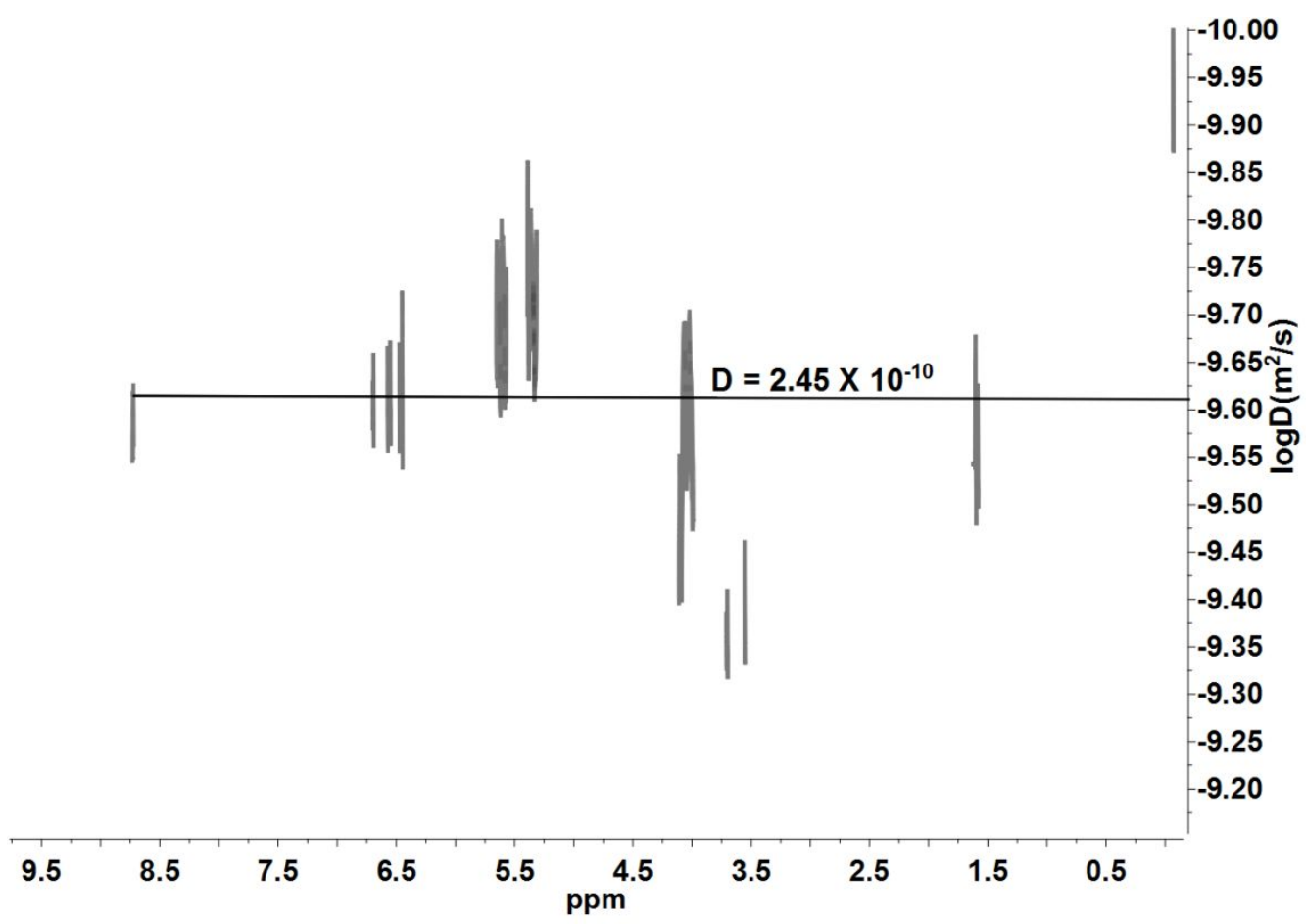

Figure S9. DOSY spectrum of Vio-Np-Vio + 1.0 equiv. CB[8] 


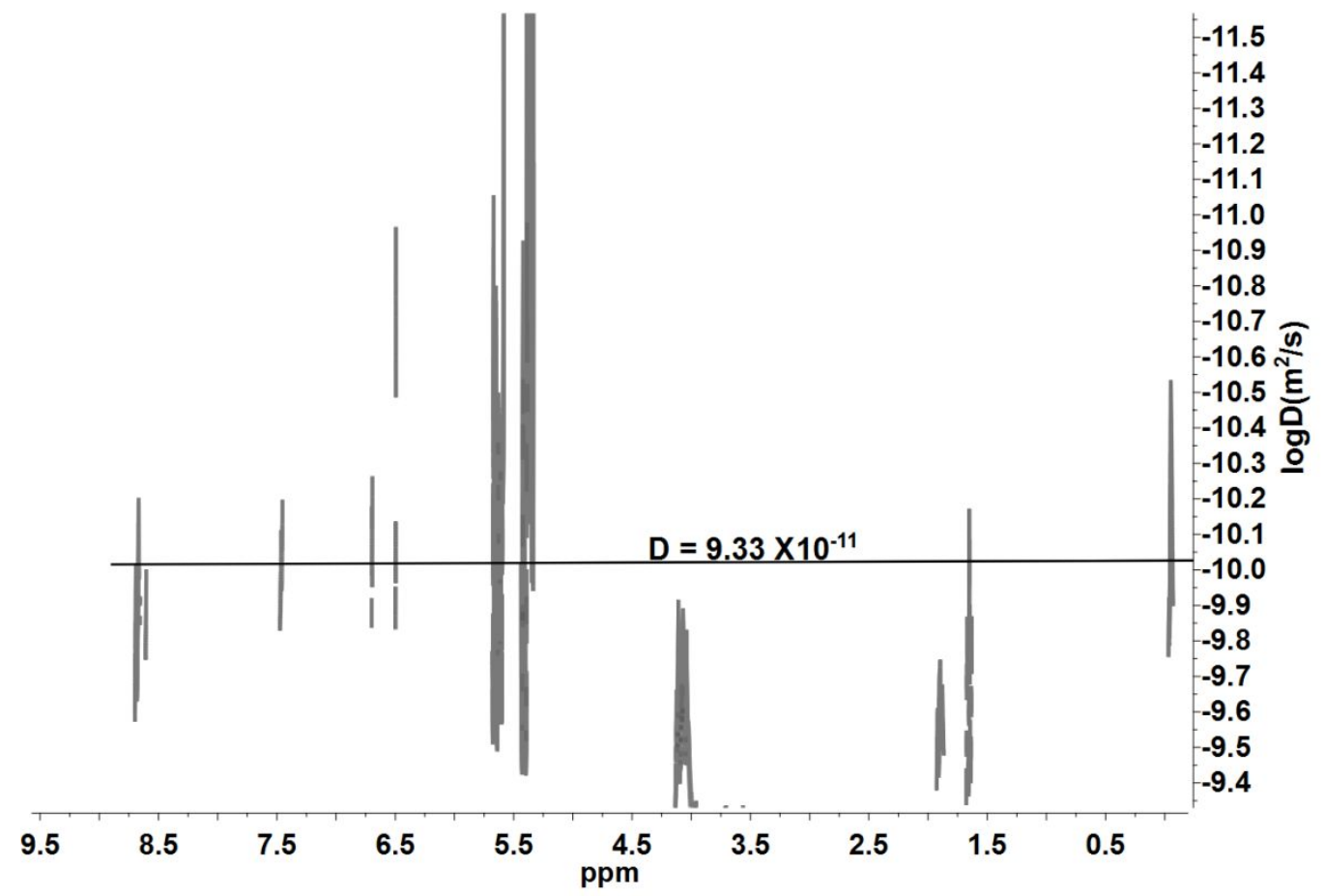

Figure S10. DOSY spectrum of Vio-Np-Vio + 2.0 eq. CB[8]

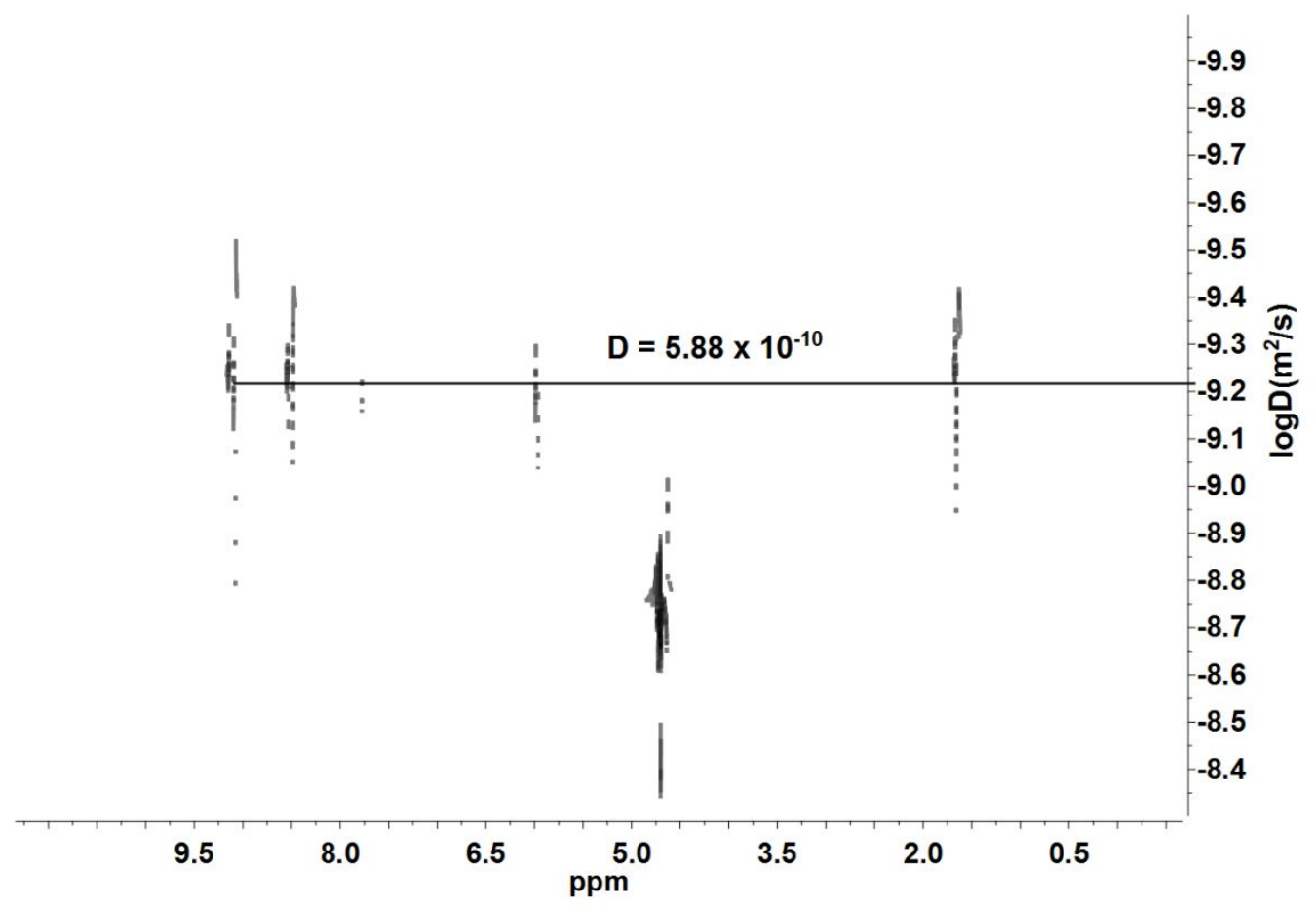

Figure S11. DOSY spectrum of ETV 


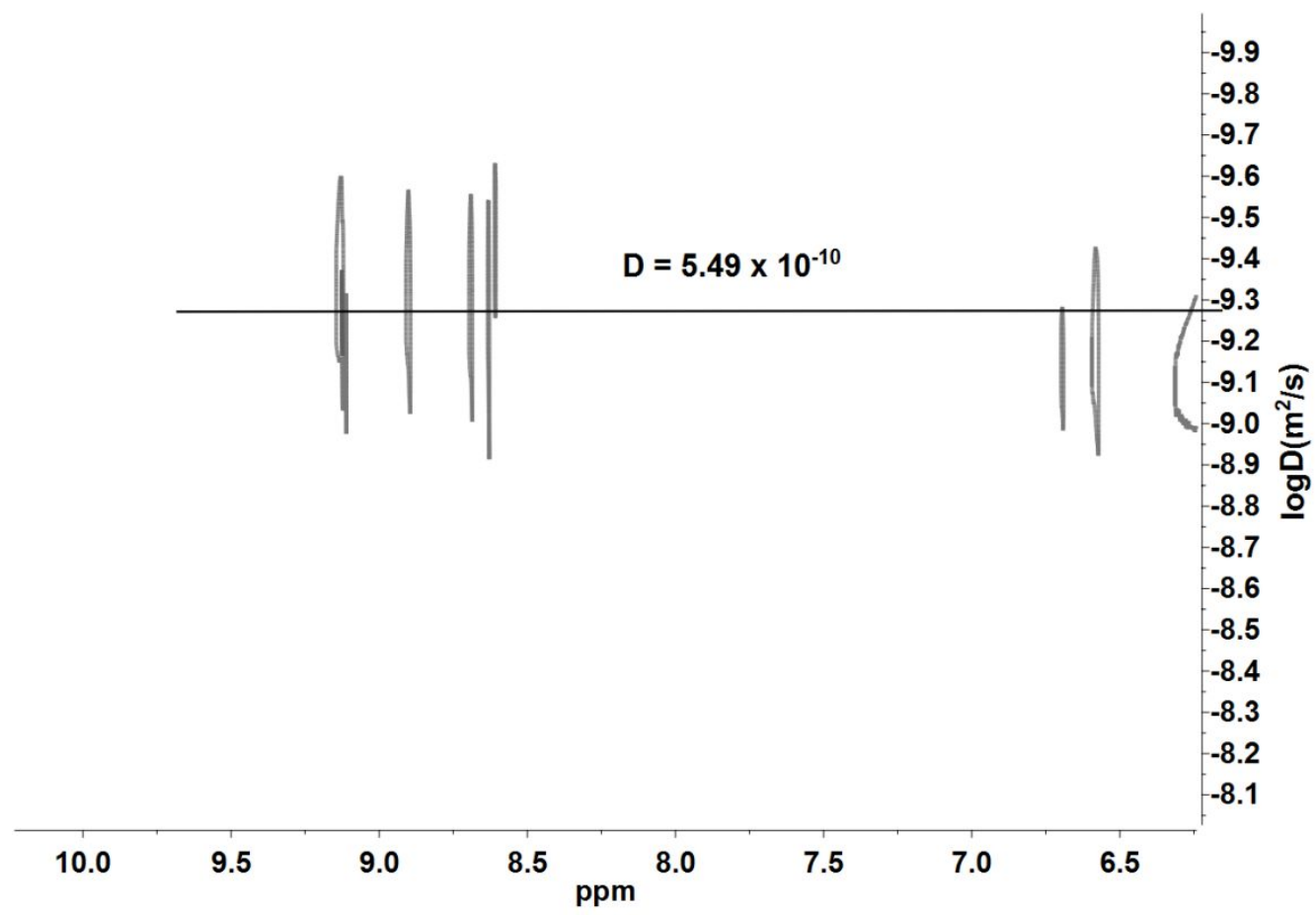

Figure S12. DOSY spectrum of ETV $+\mathbf{3 . 0}$ eq. $\mathbf{C B}[\mathbf{8}]$

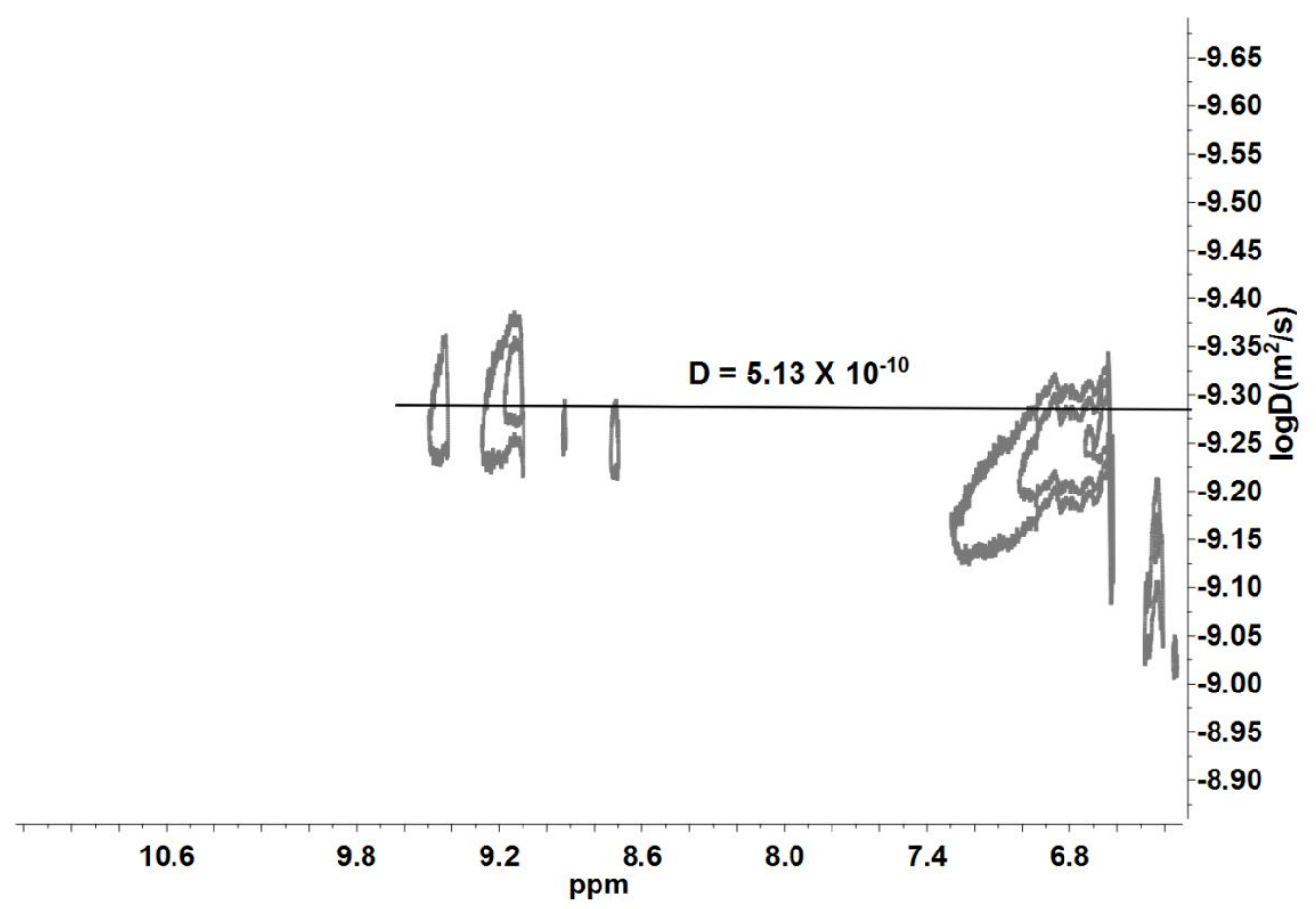

Figure S13. DOSY spectrum of ETV +3.0 eq. CB $[8]+1.0$ eq. Np-Vio-NP 


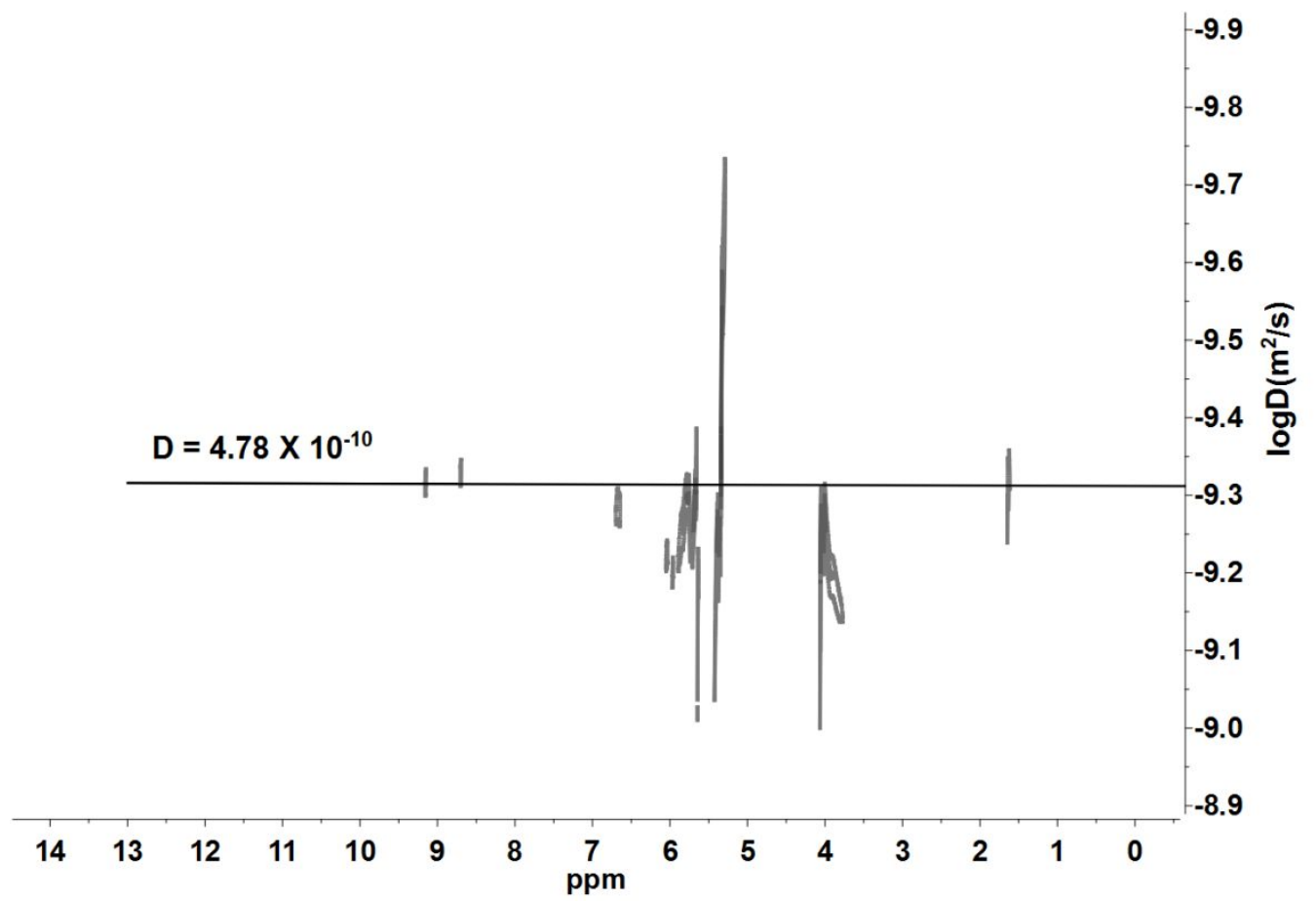

Figure S14. DOSY spectrum of ETV + 3.0 eq. CB[8] + 2.0 eq. Np-Vio-NP

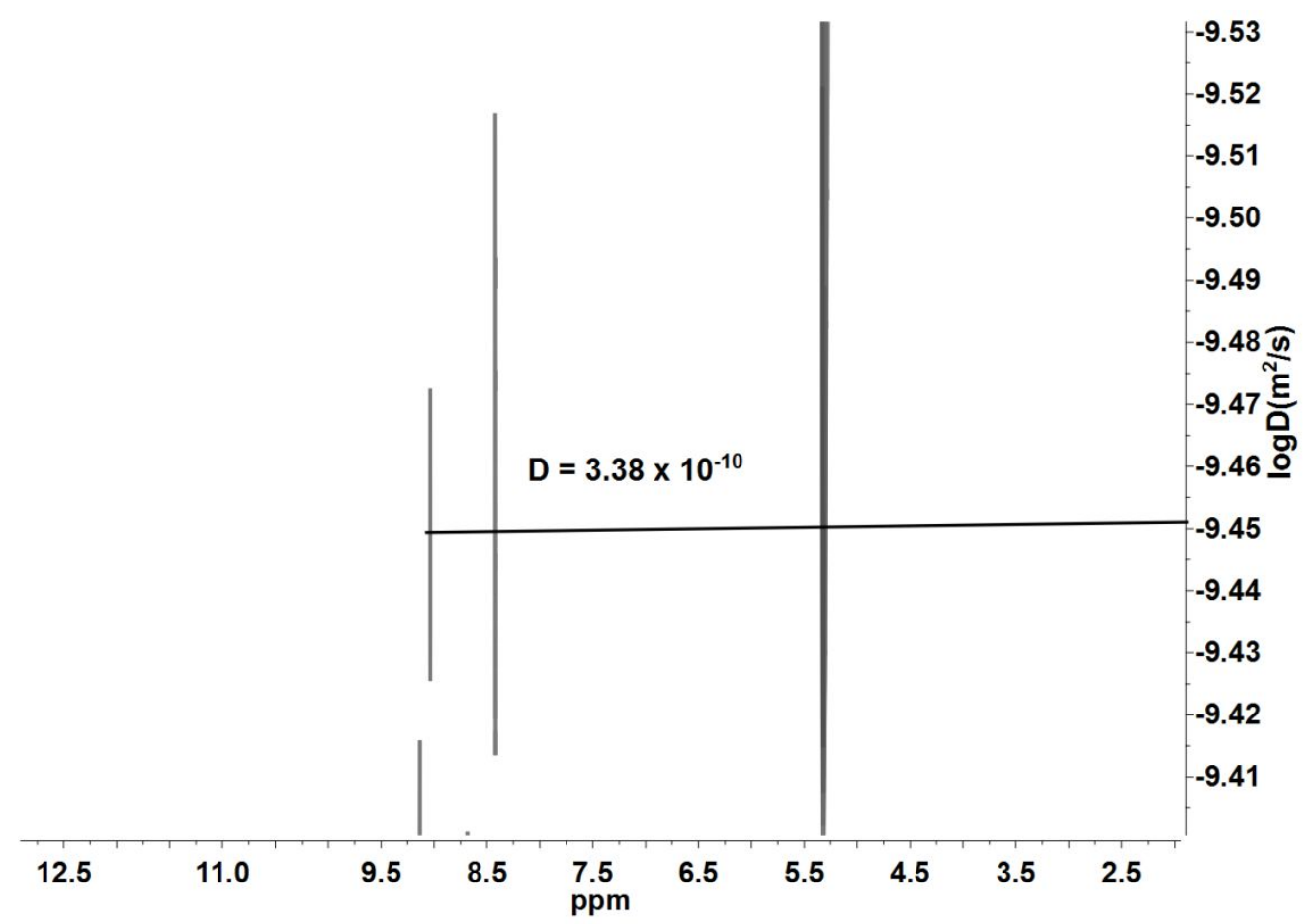

Figure S15. DOSY spectrum of ETV + 3.0 eq. CB $[8]+3.0$ eq. Np-Vio-NP 


\section{FESEM image of monomers (Np-Vio-Np, Vio-Np-Vio and ETV)}
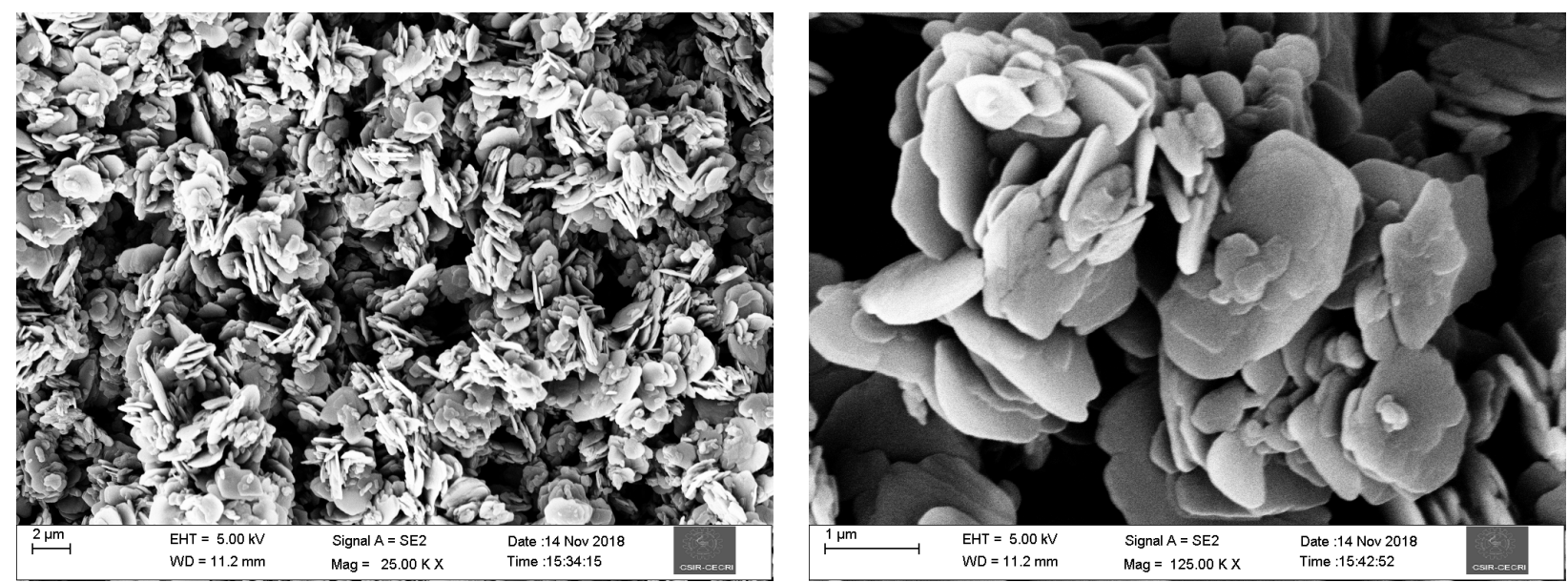

Figure S16. FESEM images of Np-Vio-Np
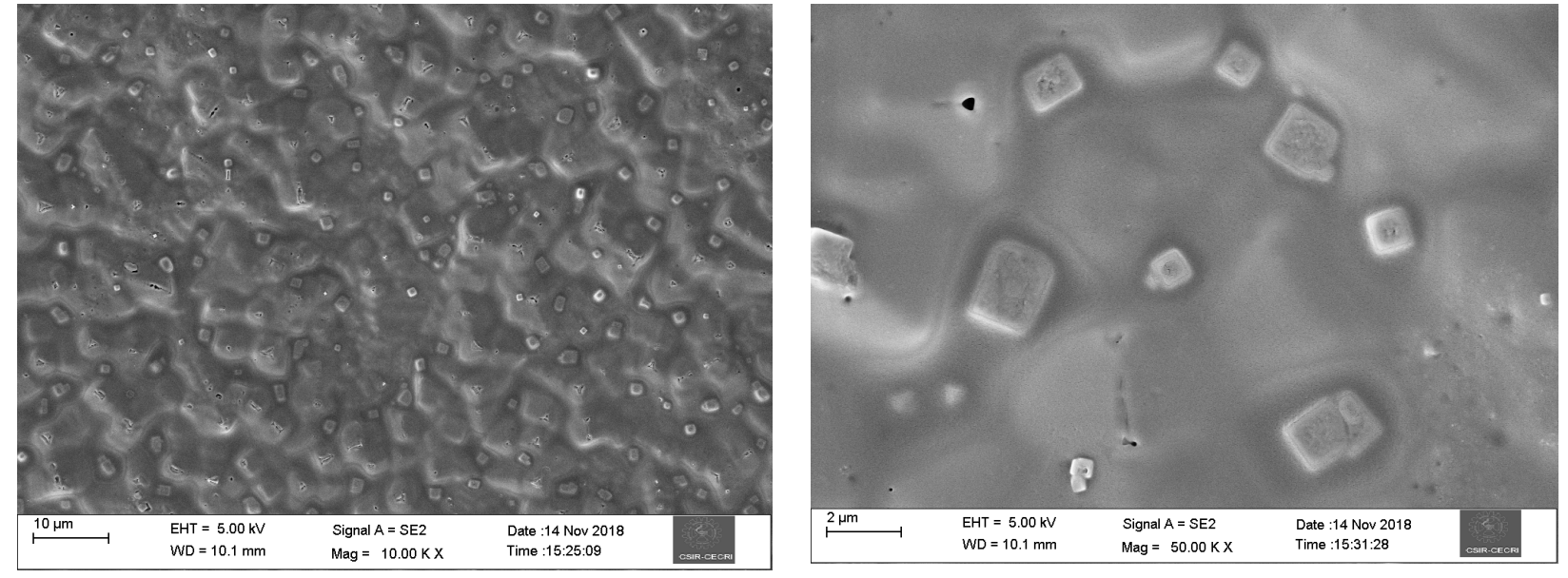

Figure S17. FESEM images of Vio-Np-Vio
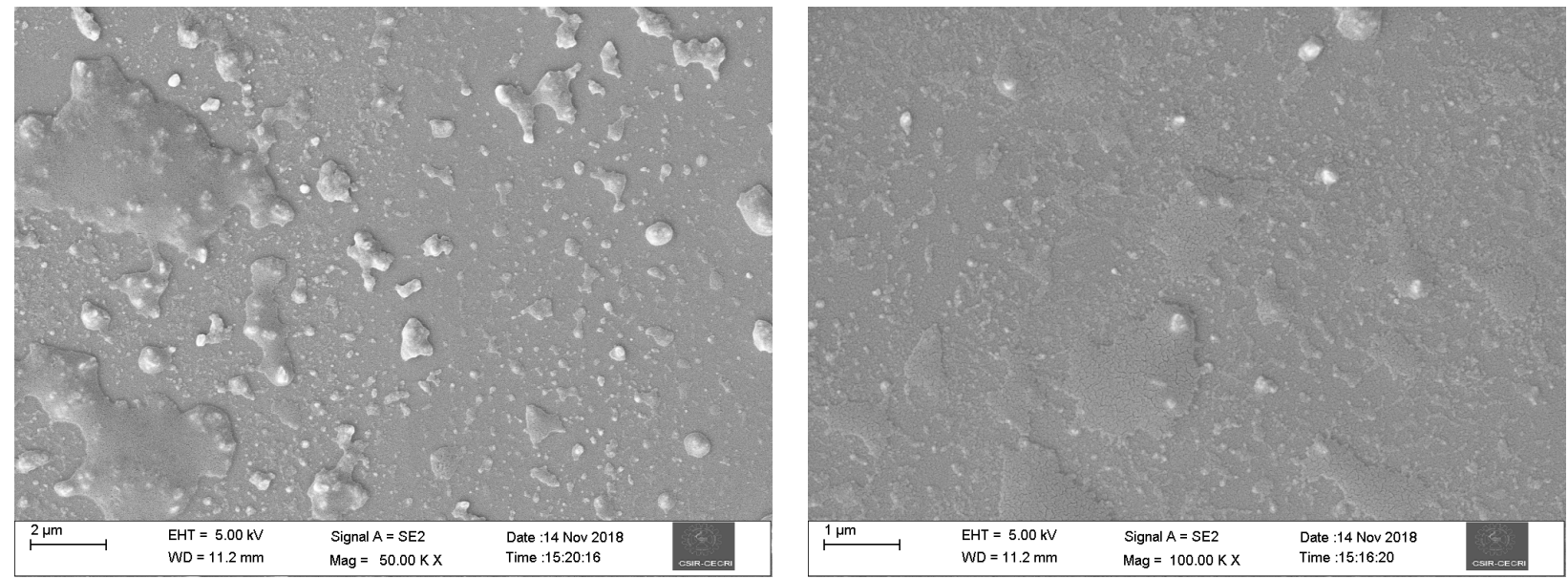

Figure S18. FESEM images of ETV 
FESEM images of the monomers showed islands of monomers in the case of Vio-Np-Vio and ETV, on contrary Np-Vio-Np showed larger aggregates which is further confirmed by TEM. Formation of large aggregates can be ascribed to the hydrophobic naphthyl periphery which dislikes water; as a result this Np-Vio-Np forms large aggregates in water. To verify this further, particle size and zeta potential measurements were carried out.

\section{Particle size and Zeta-potential measurements for uncomplexed Np-Vio-Np in water}
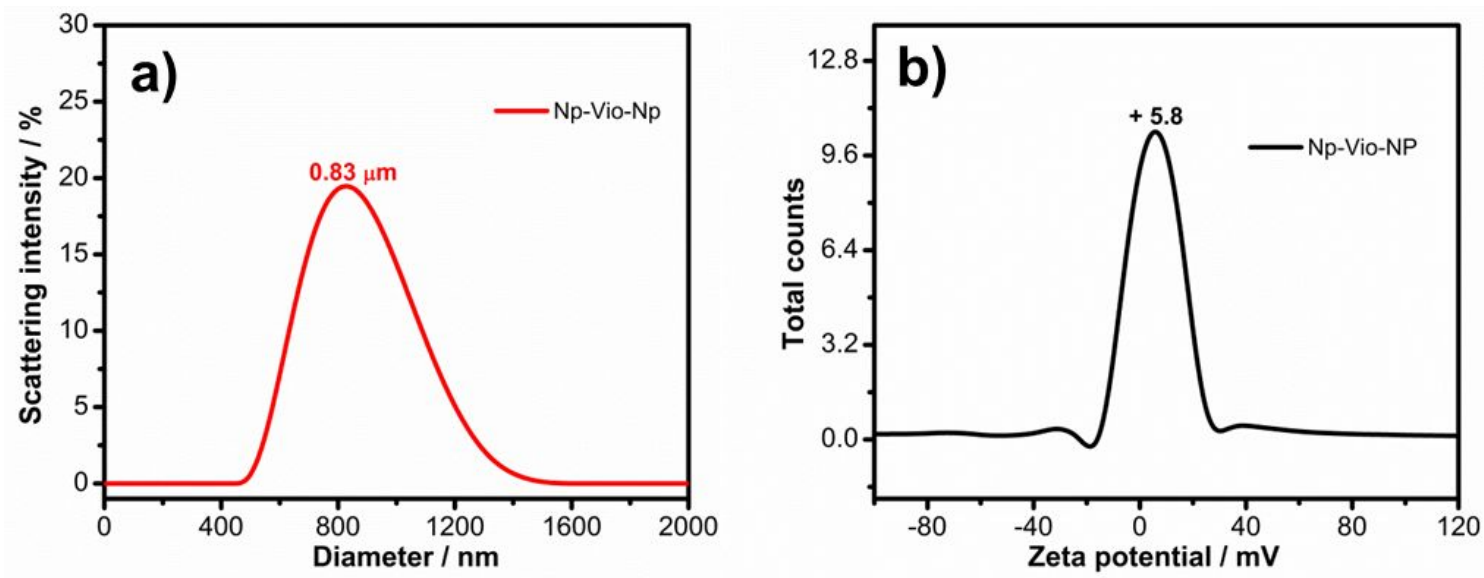

Figure S19. a) particle size measurements and b) zeta potential measurements for uncomplexed Np-Vio-Np in water.

Particle size measurements indicate an average particle size of $0.83 \mu \mathrm{m}$ for free $\mathrm{Np}-\mathrm{Vio}-\mathrm{Np}$ molecule which matches very well with the obtained FESEM and TEM results. Further zeta potential measurements were carried out, and $+5.8 \mathrm{mV}$ was obtained for free $\mathrm{Np}-\mathrm{Vio}-\mathrm{Np}$ indicative of rapid coagulation. 


\section{TEM images of Np-Vio-Np without complexation}
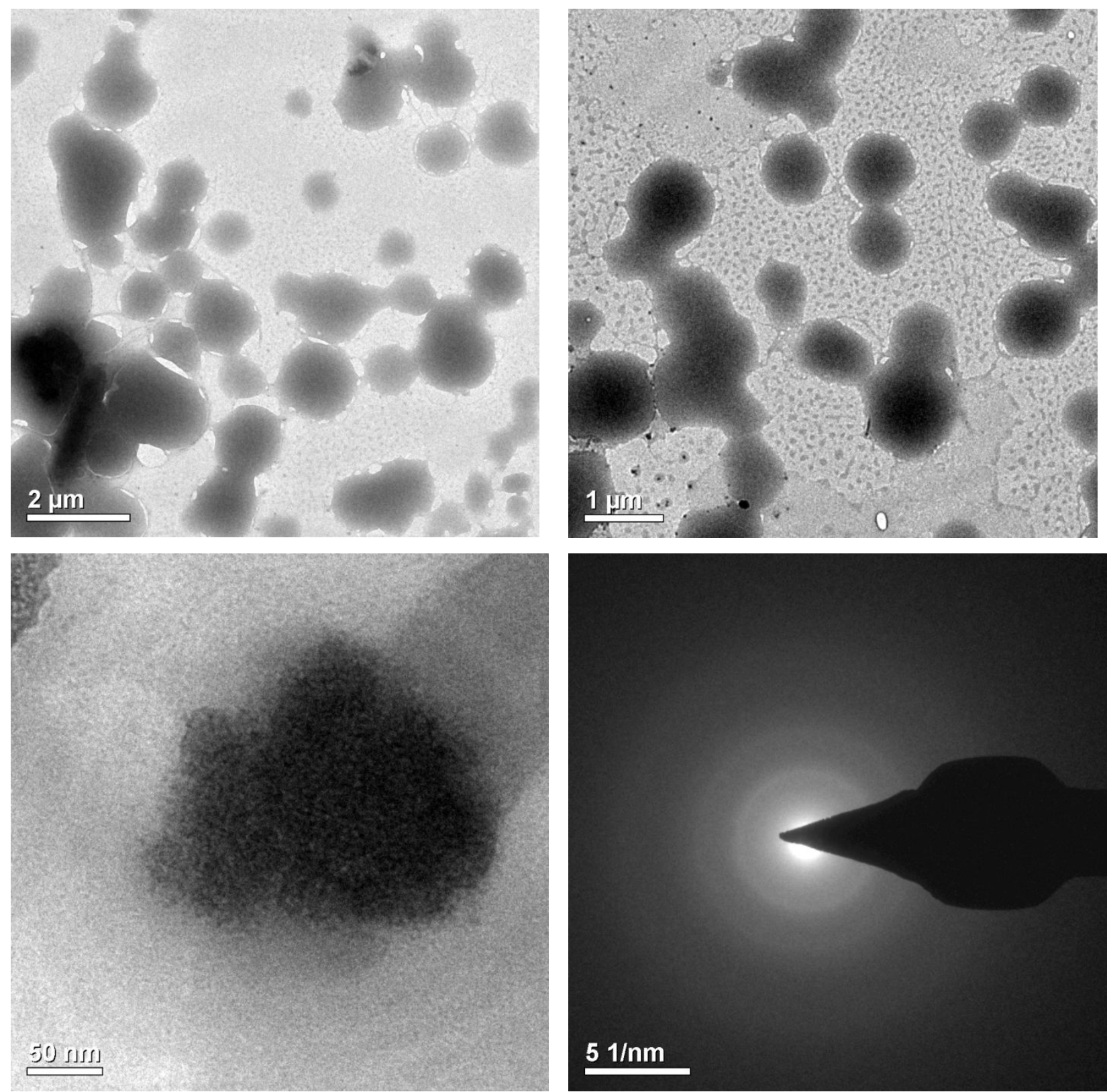

Figure S20. TEM images of Np-Vio-Np (uncomplexed) 
10. $\underline{{ }^{1} \mathrm{H},{ }^{13} \mathrm{C}, \text { DEPT NMR and ESI spectrum of synthesized compounds }}$
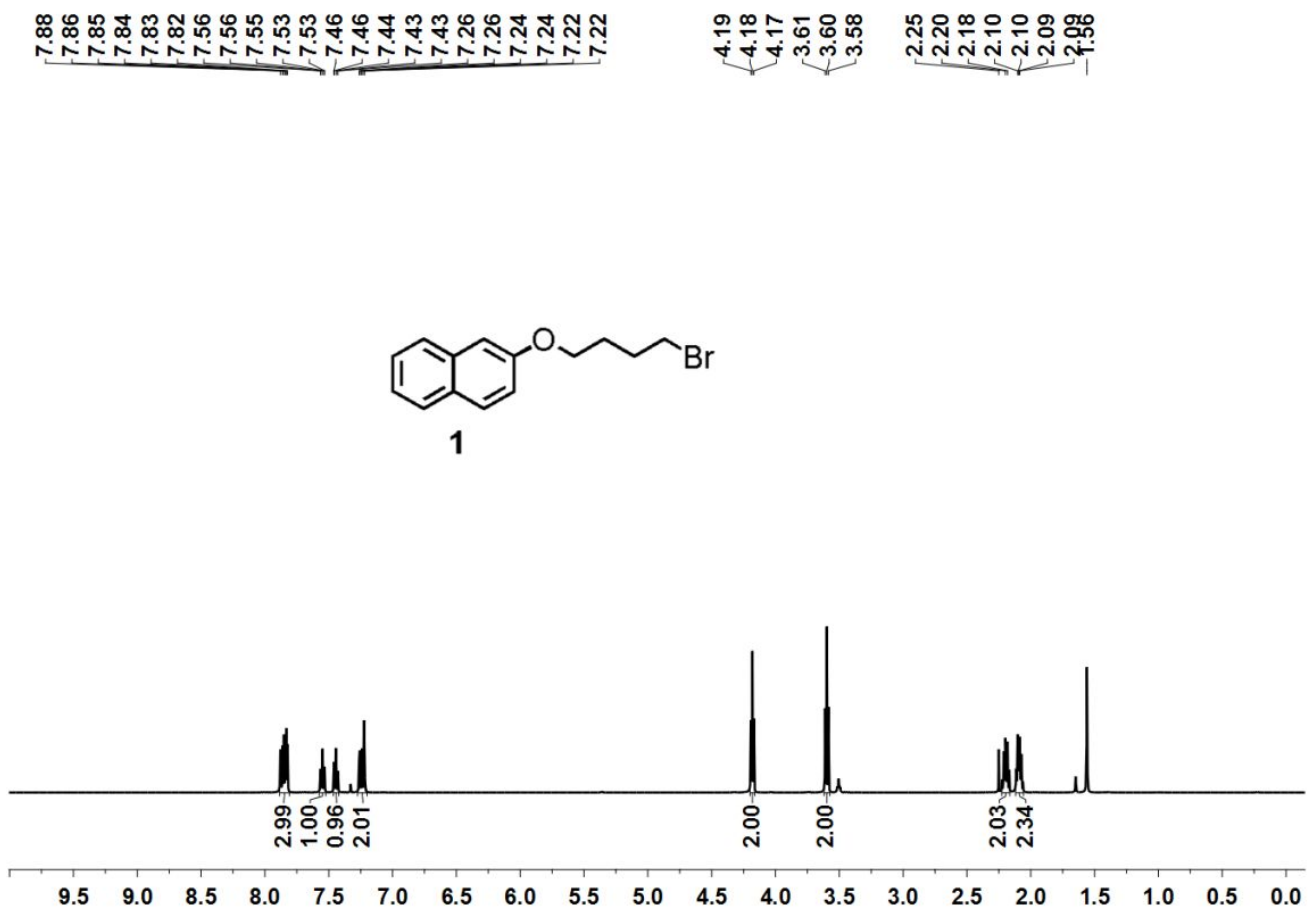

Figure S21. ${ }^{1} \mathrm{H}$ NMR spectrum of compound 1

\begin{tabular}{|c|c|c|}
\hline 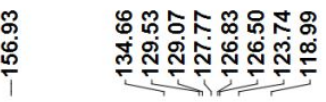 & $\begin{array}{l}\ddot{\vdots} \\
\stackrel{0}{1}\end{array}$ & 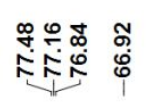 \\
\hline
\end{tabular}

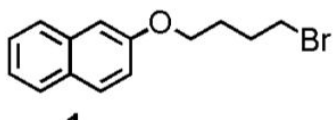

1

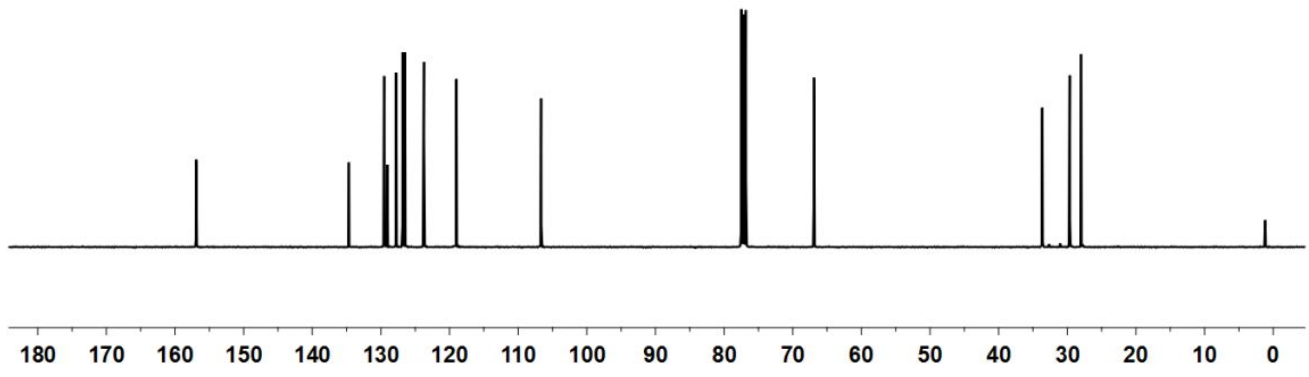

Figure S22. ${ }^{13} \mathrm{C}$ NMR spectrum of compound 1 

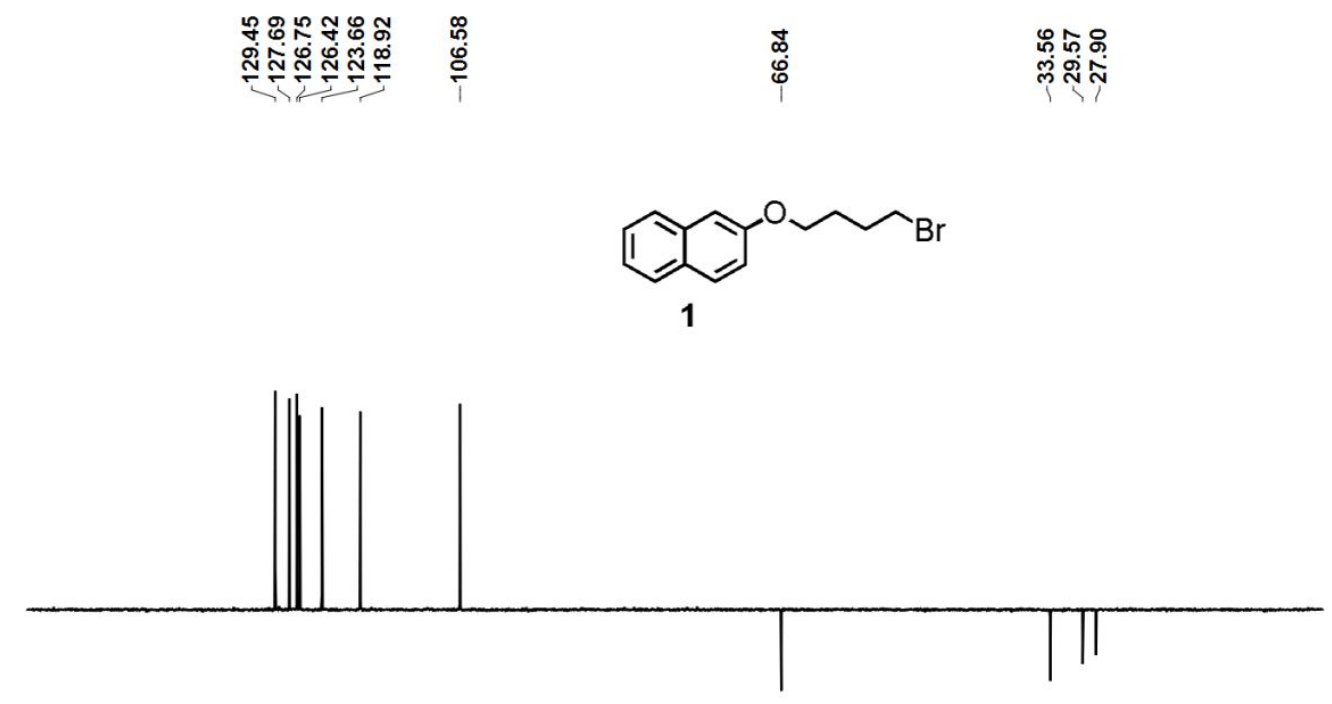

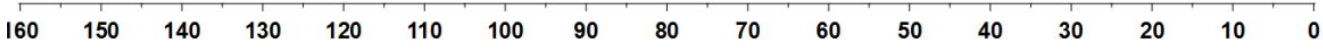

Figure S23. DEPT NMR spectrum of compound 1

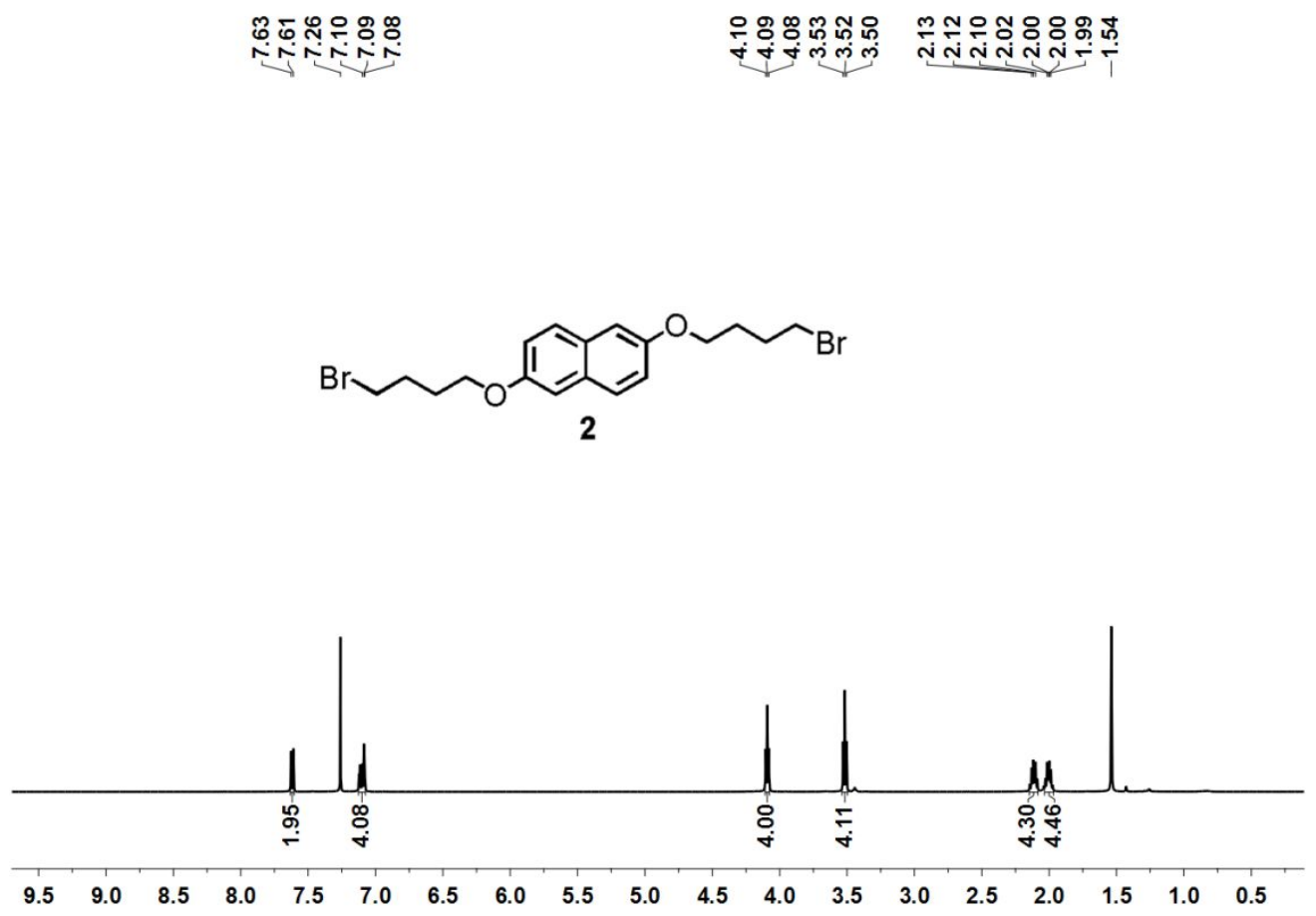

Figure S24. ${ }^{1} \mathrm{H}$ NMR spectrum of compound 2 


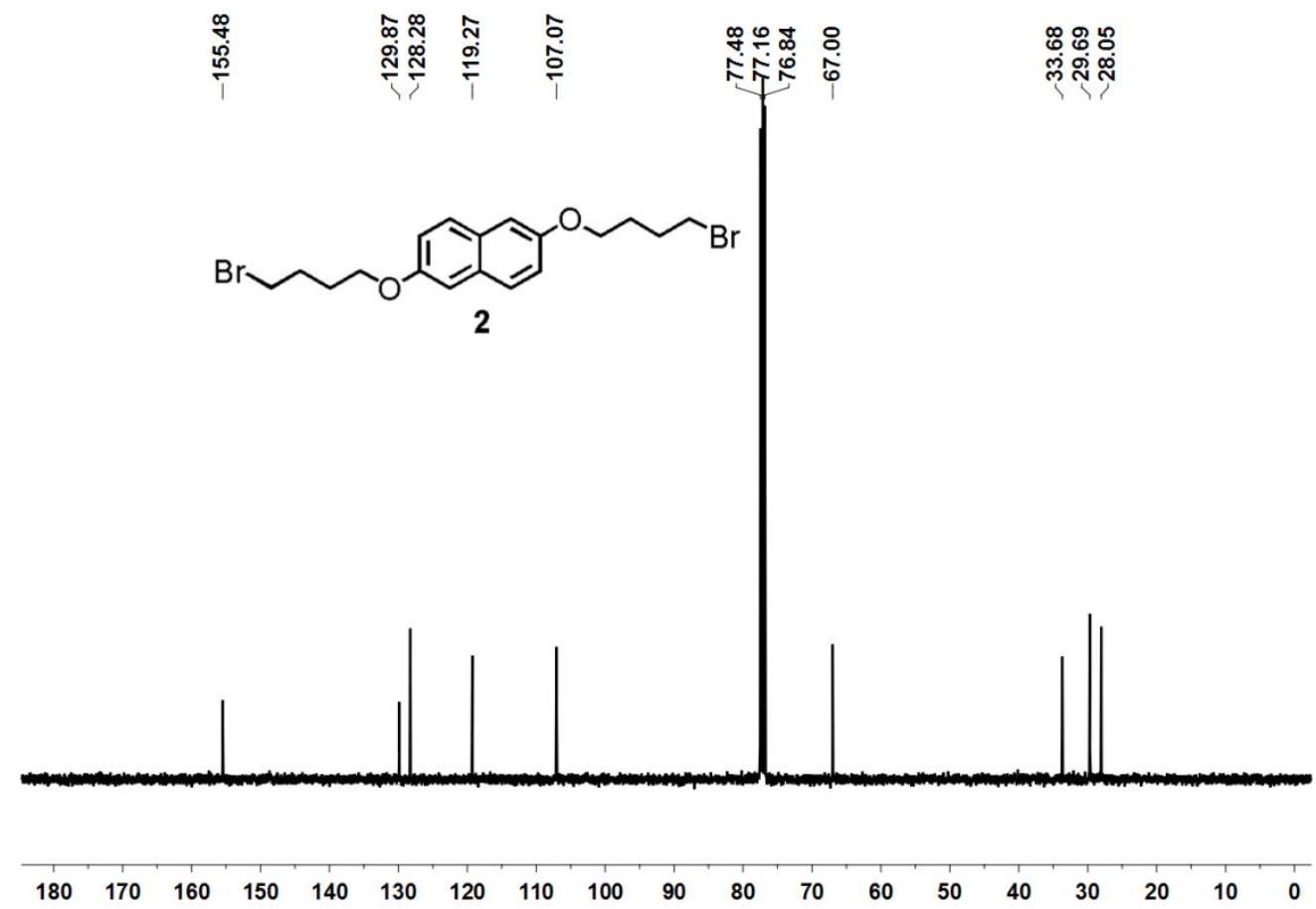

Figure S25. ${ }^{13} \mathrm{C}$ NMR spectrum of compound 2
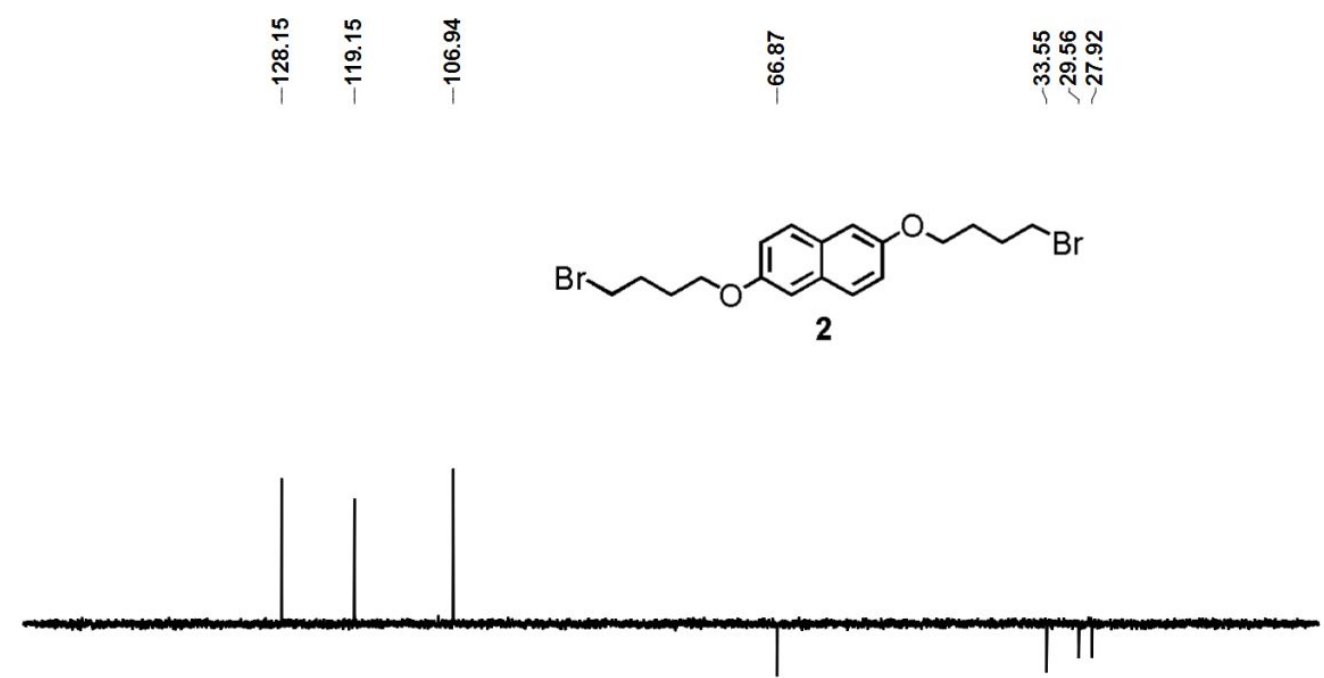

Figure S26. DEPT NMR spectrum of compound 2 
$\mathrm{PF}_{6}^{-}$<smiles></smiles>

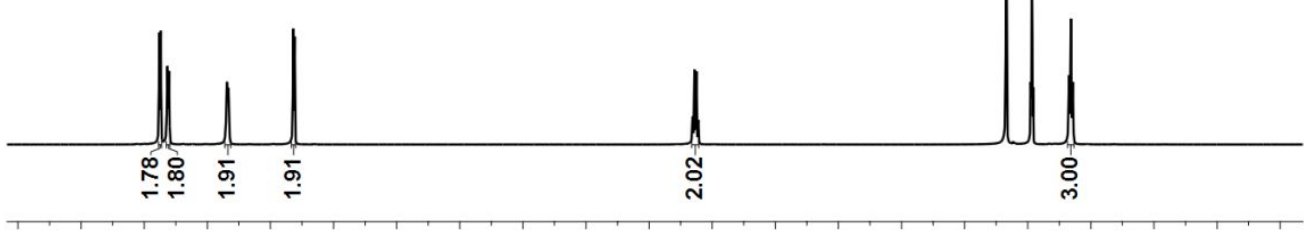

Figure S27. ${ }^{1} \mathrm{H}$ NMR spectrum of compound 3

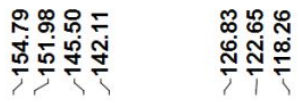
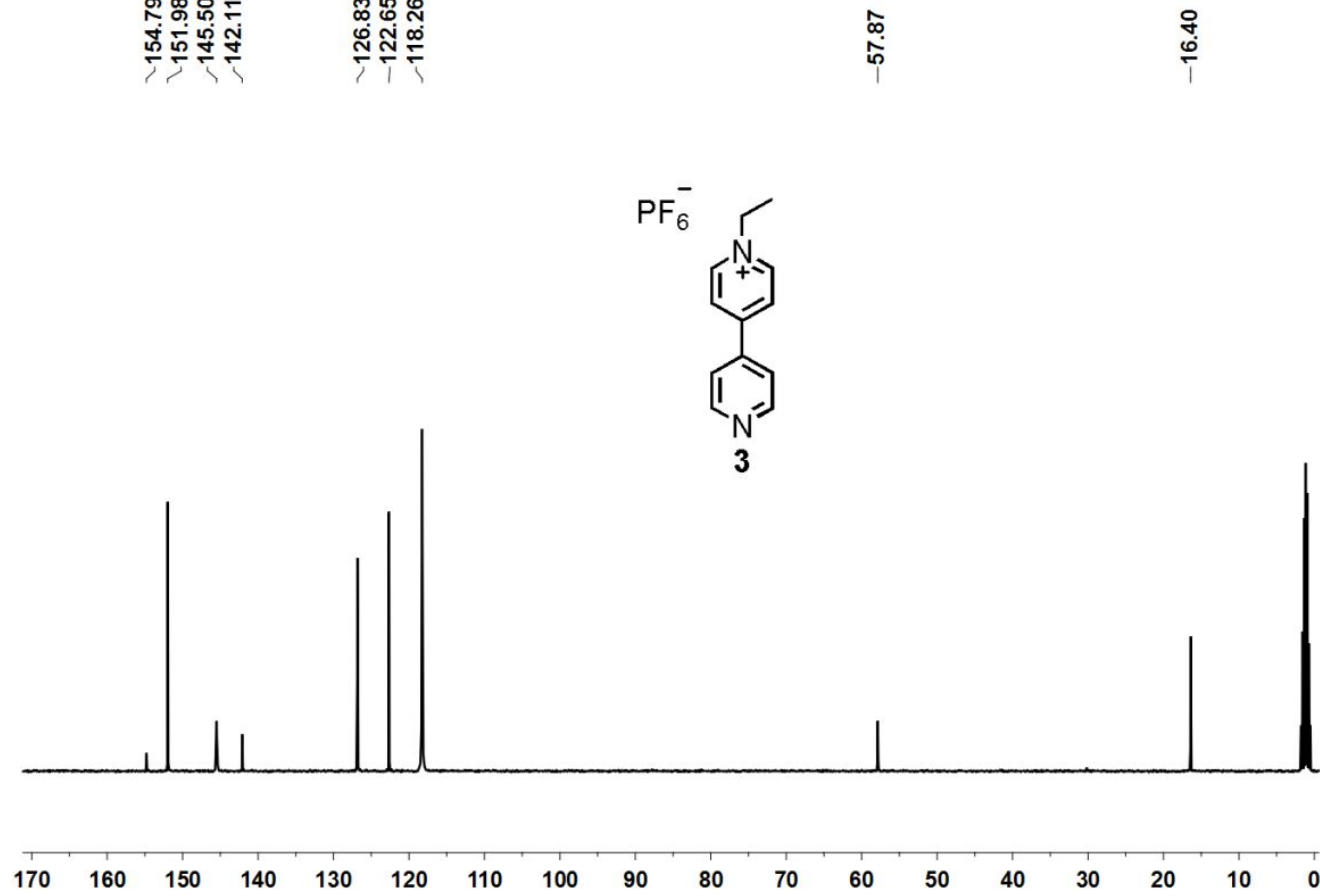

Figure S28. ${ }^{13} \mathrm{C}$ NMR spectrum of compound 3 


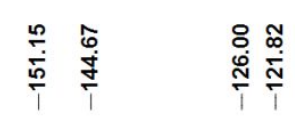
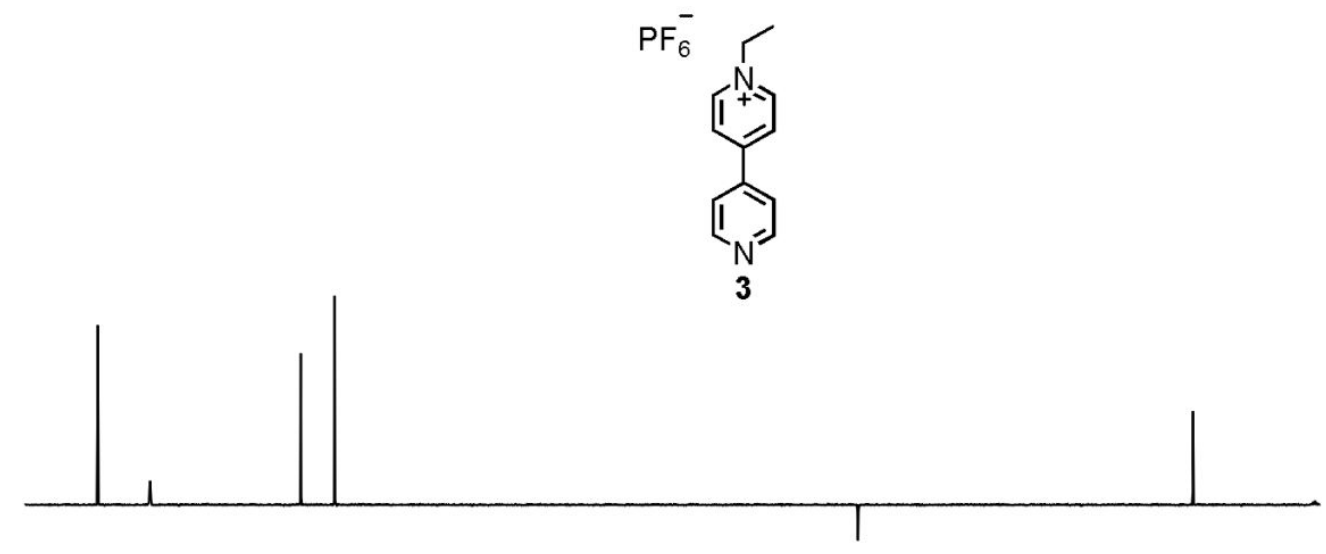

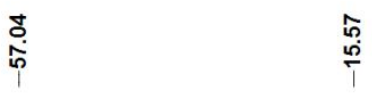

\begin{tabular}{llllllllllllllllll}
160 & 150 & 140 & 130 & 120 & 110 & 100 & 90 & 80 & 70 & 60 & 50 & 40 & 30 & 20 & 10 & 0 \\
\hline
\end{tabular}

Figure S29. DEPT NMR spectrum of compound 3

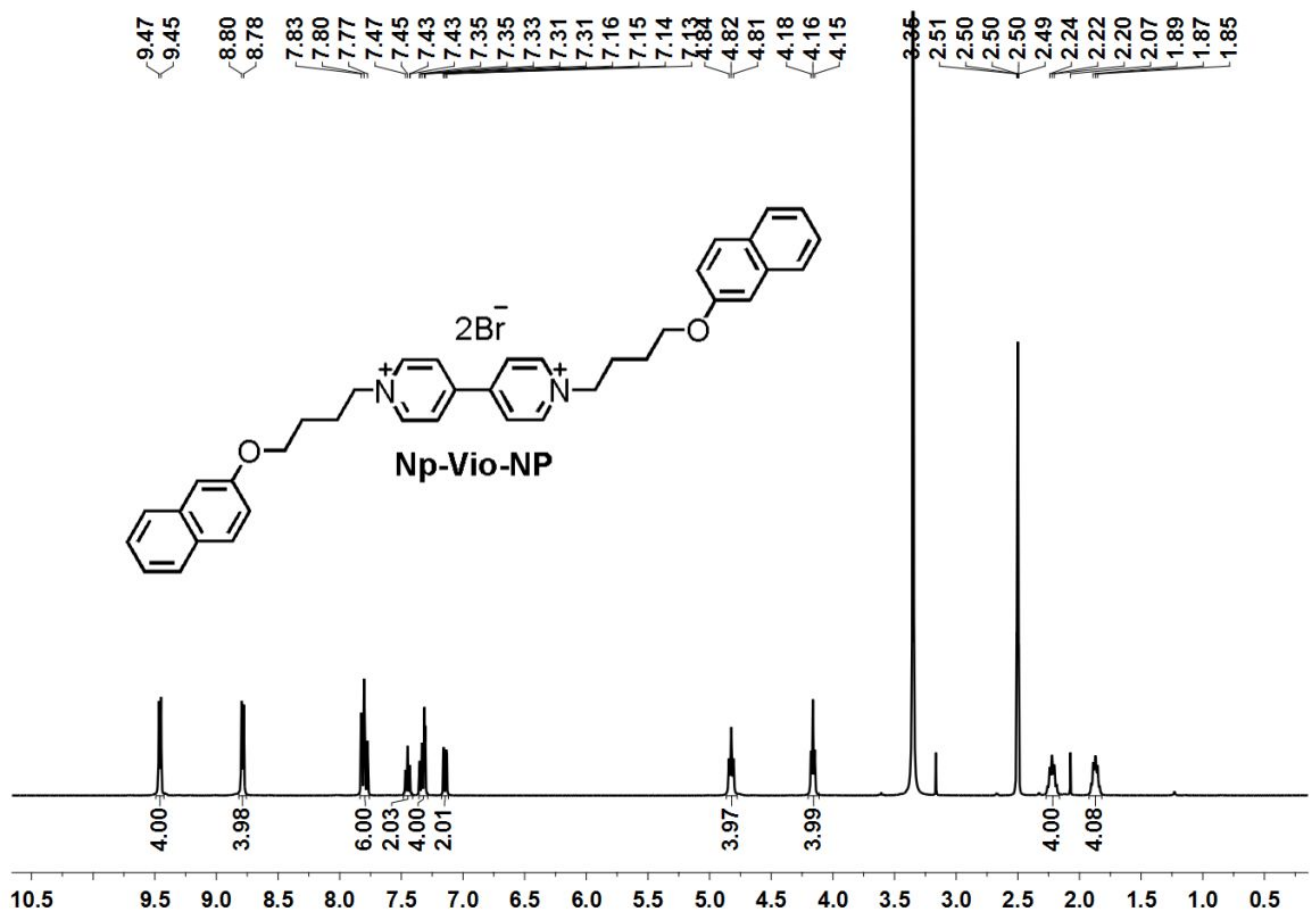

Figure S30. ${ }^{1} \mathrm{H}$ NMR spectrum of compound Np-Vio-NP 


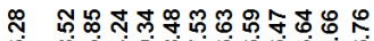

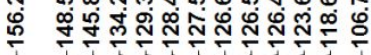

\section{$\begin{array}{ll}\infty & 0 \\ 0 & 0 \\ 0 & 0 \\ 1 & 1\end{array}$}

iิ
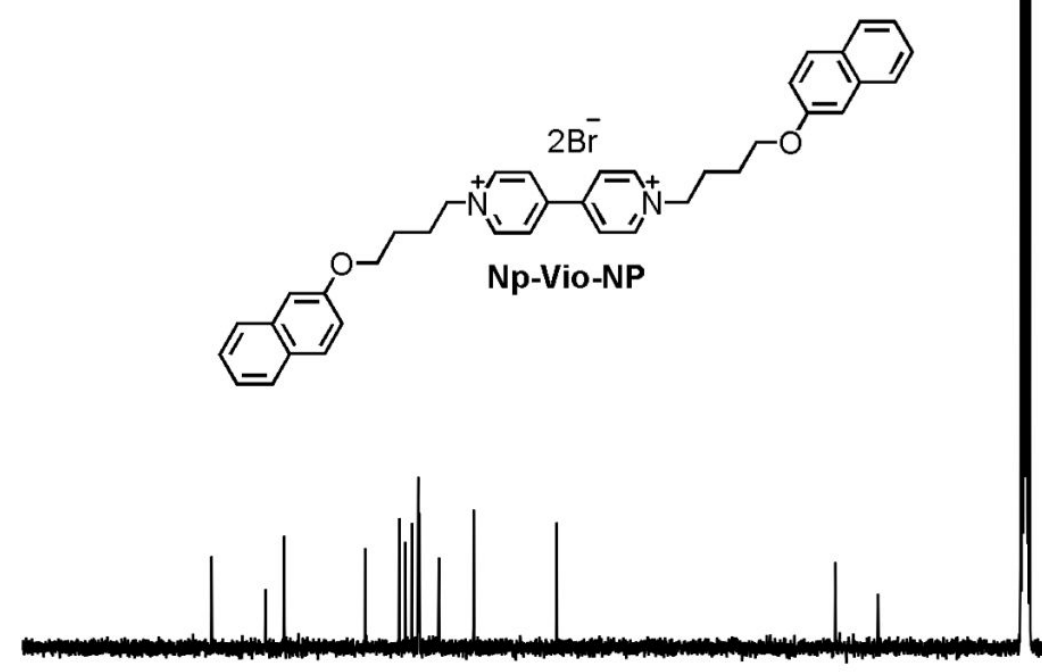

180

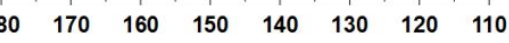

Figure S31. ${ }^{13} \mathrm{C}$ NMR spectrum of compound Np-Vio-NP

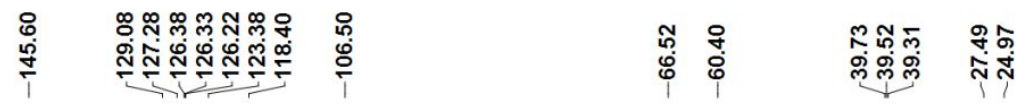

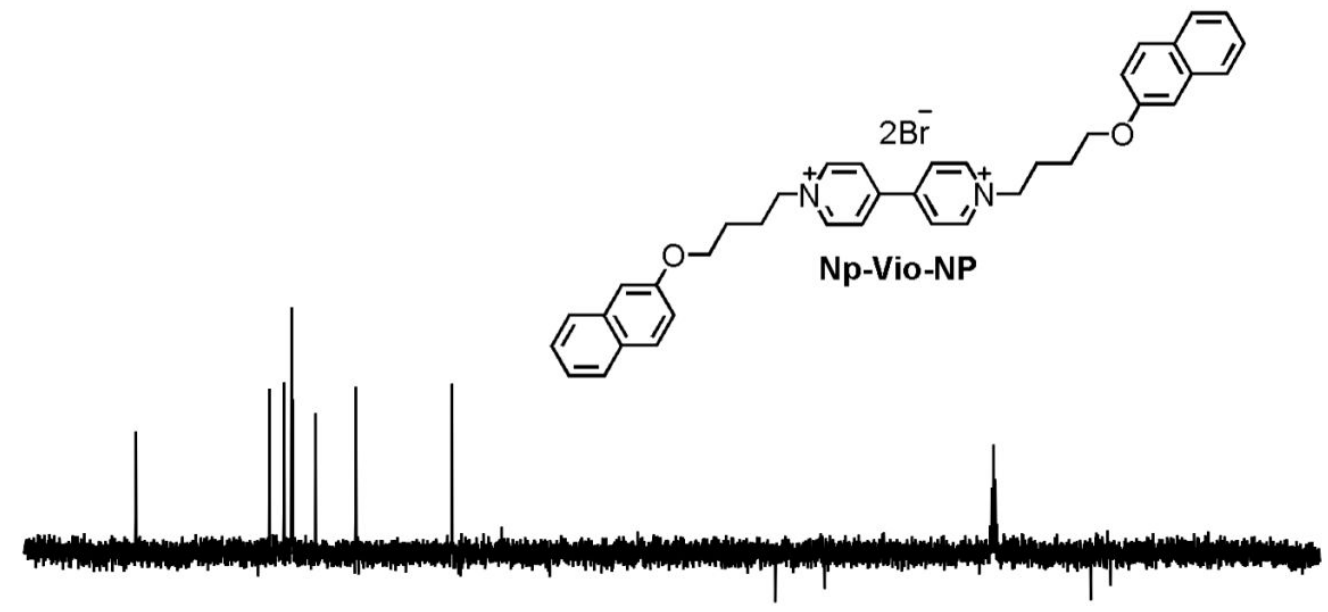

$\begin{array}{llllll}150 & 140 & 130 & 120 & 110 & 100\end{array}$

Figure S32. DEPT NMR spectrum of compound Np-Vio-NP 


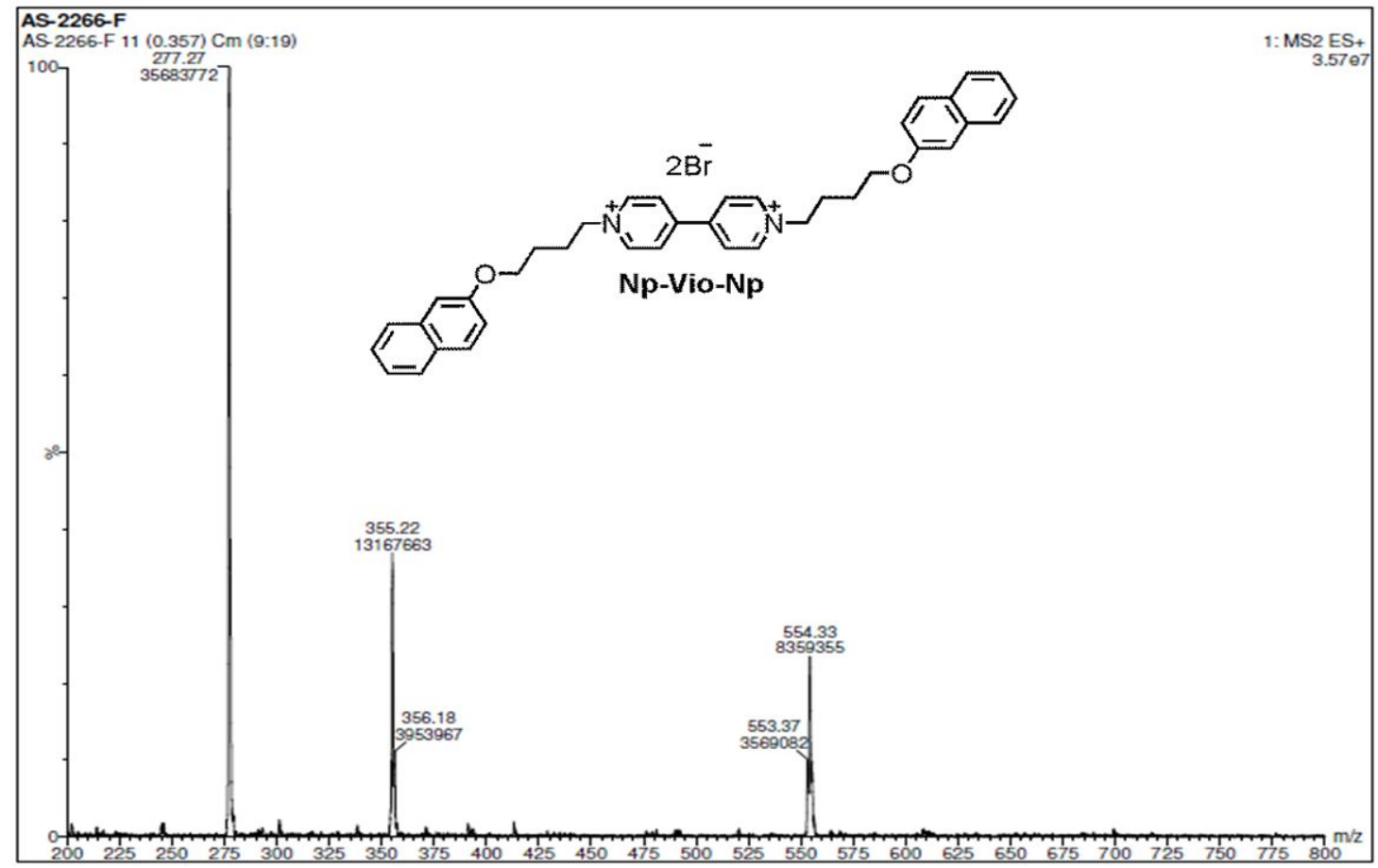

Figure S33. ESI-MS spectrum of compound Np-Vio-Np in sodium trifluoroacetate $\left((\mathrm{M}+\mathrm{Na})^{+}, \mathrm{m} / \mathrm{z}=159\right)$.

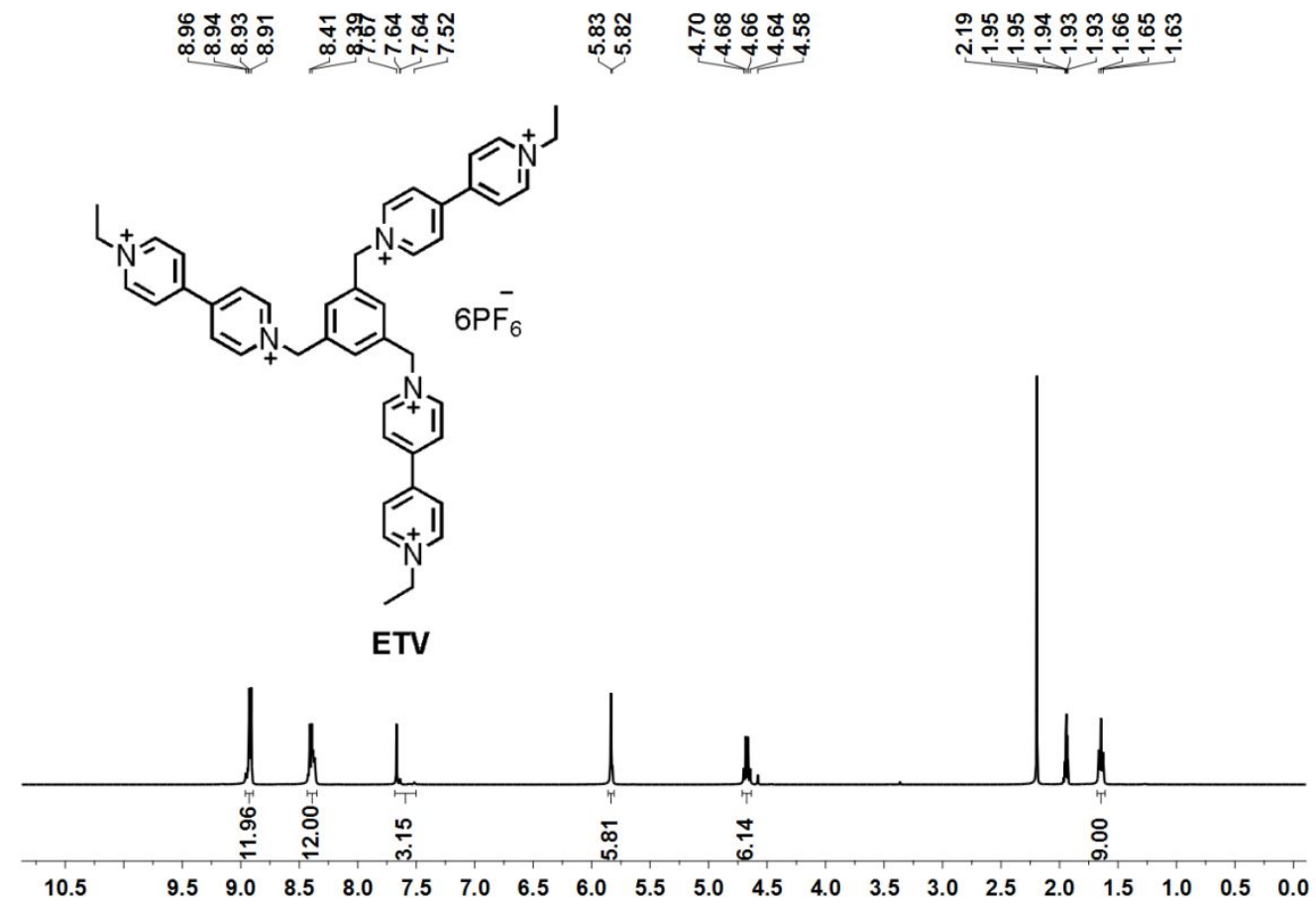

Figure S34. ${ }^{1} \mathrm{H}$ NMR spectrum of compound ETV 

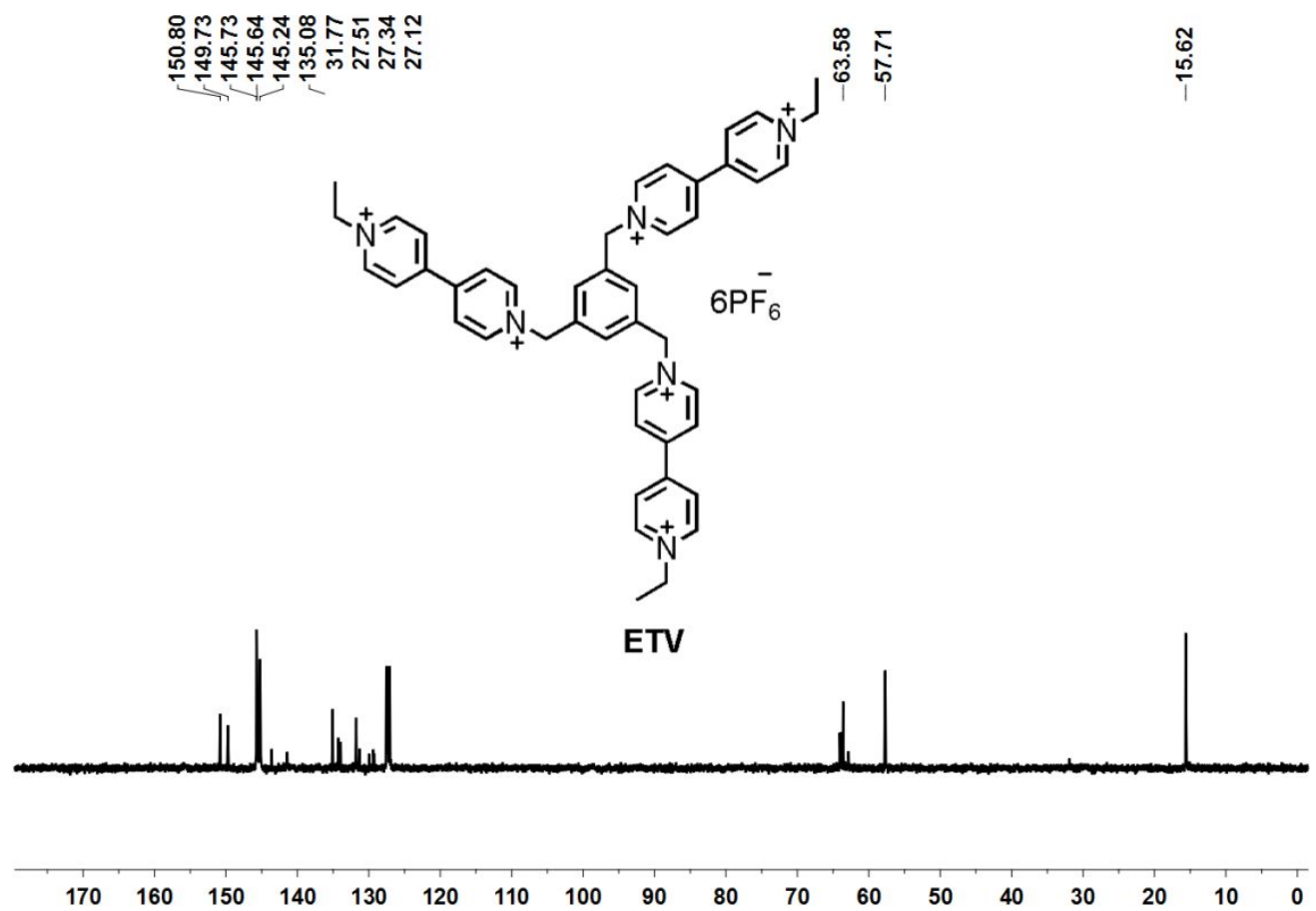

Figure S35. ${ }^{13} \mathrm{C}$ NMR spectrum of compound ETV
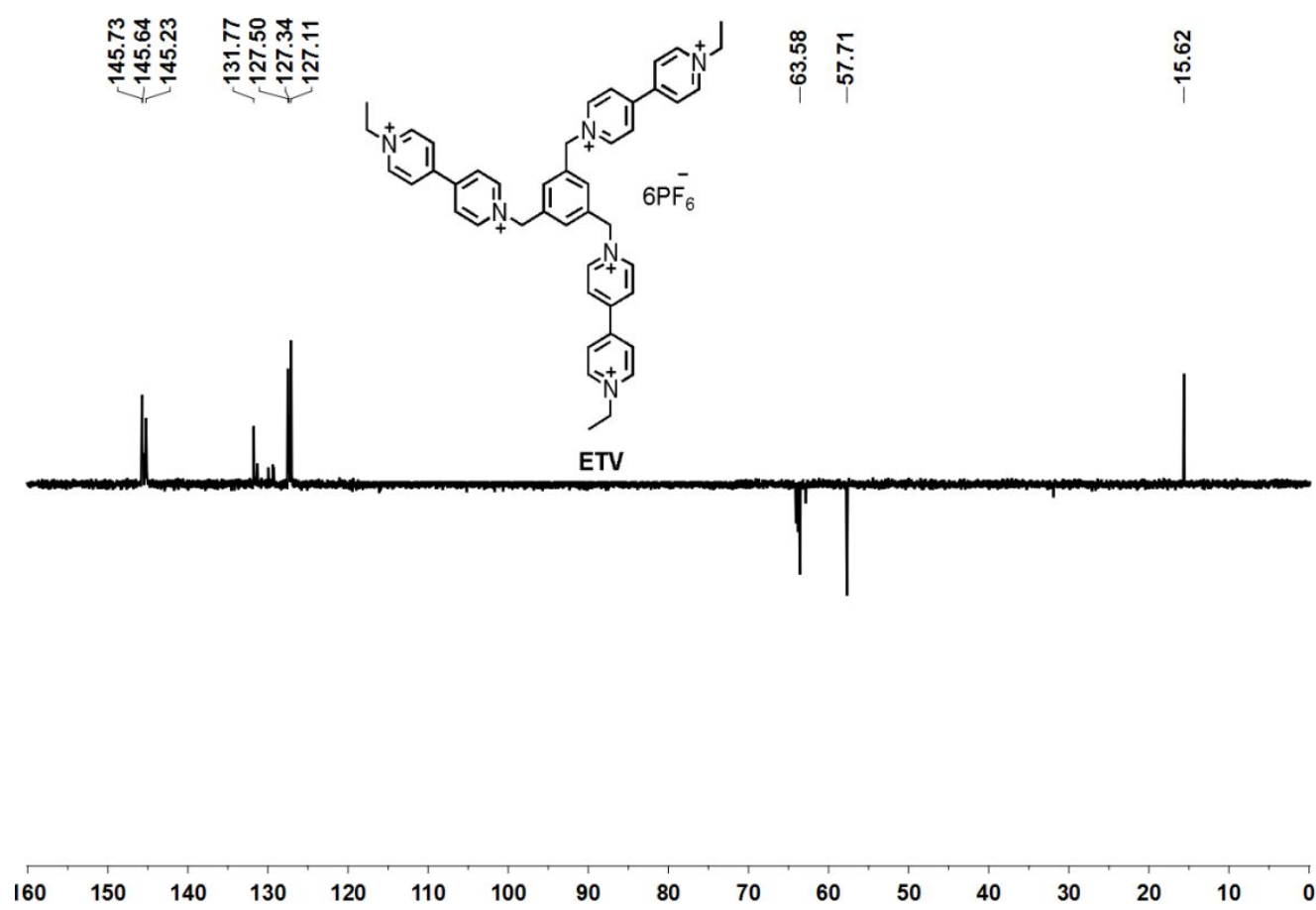

Figure S36. DEPT NMR spectrum of compound ETV 


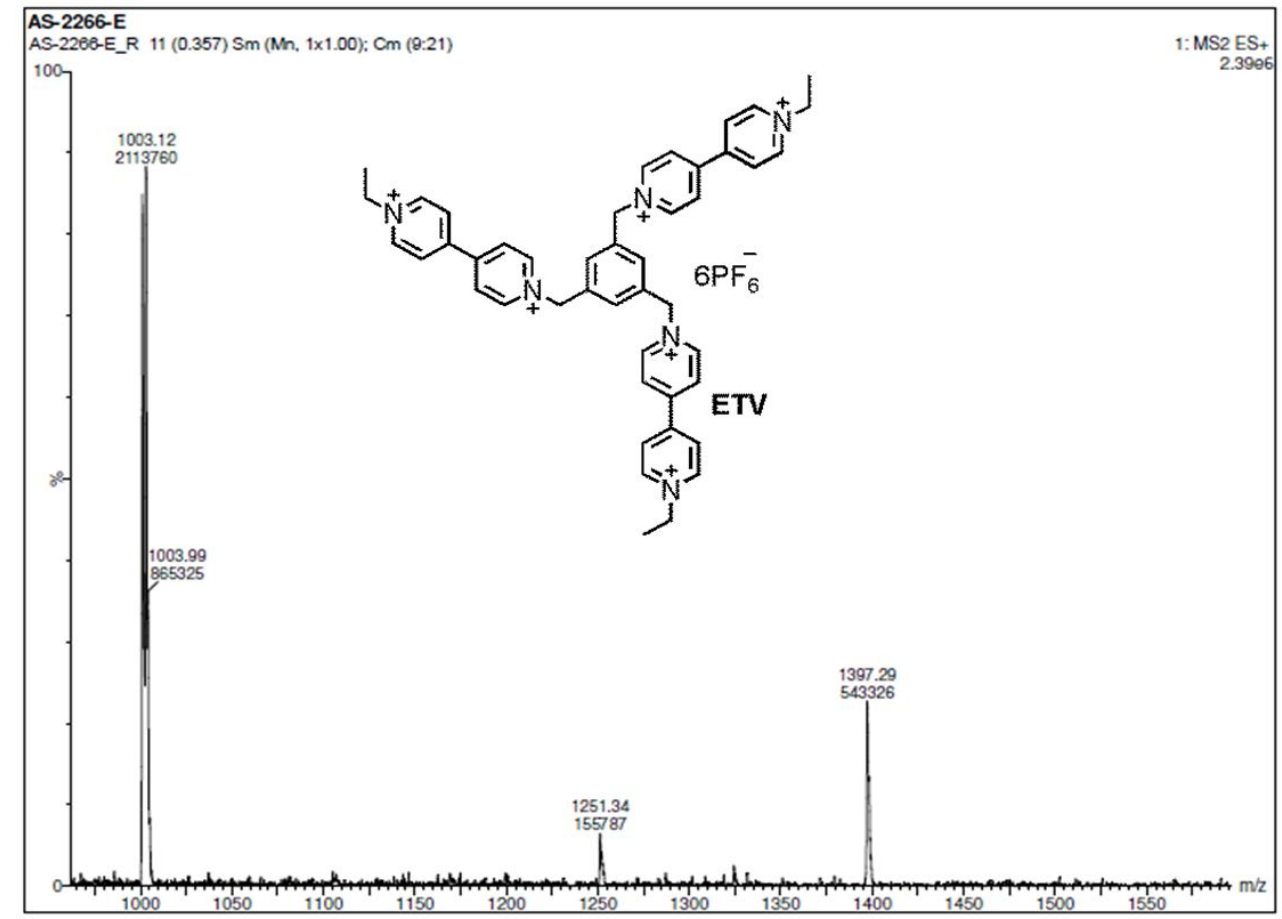

Figure S37. ESI-MS spectrum of compound ETV in acetonitrile $\left((2 \mathrm{M}+\mathrm{Cu})^{+}, \mathrm{m} / \mathrm{z}=145\right)$.

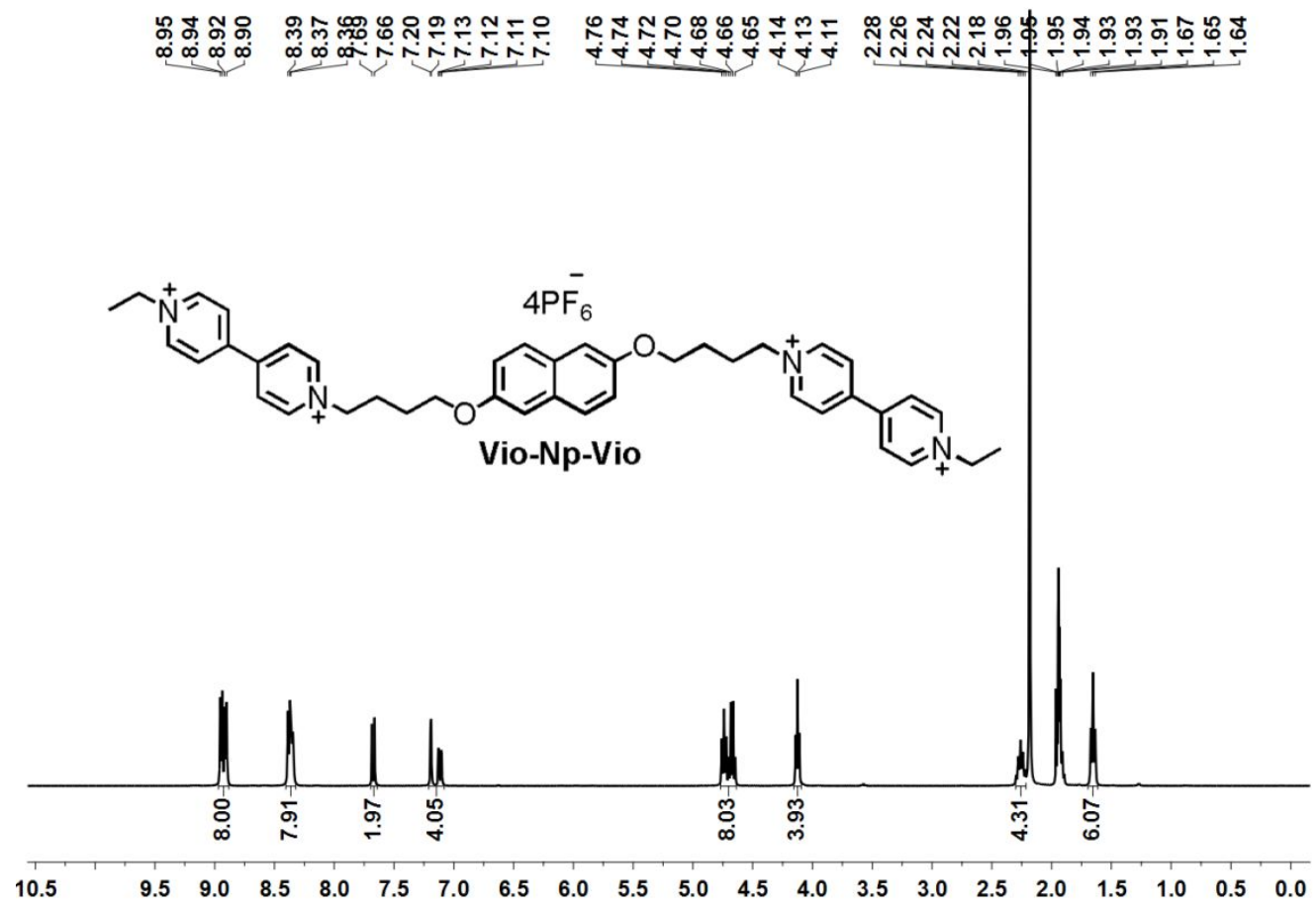

Figure S38. ${ }^{1} \mathrm{H}$ NMR spectrum of compoundVio-Np-Vio 


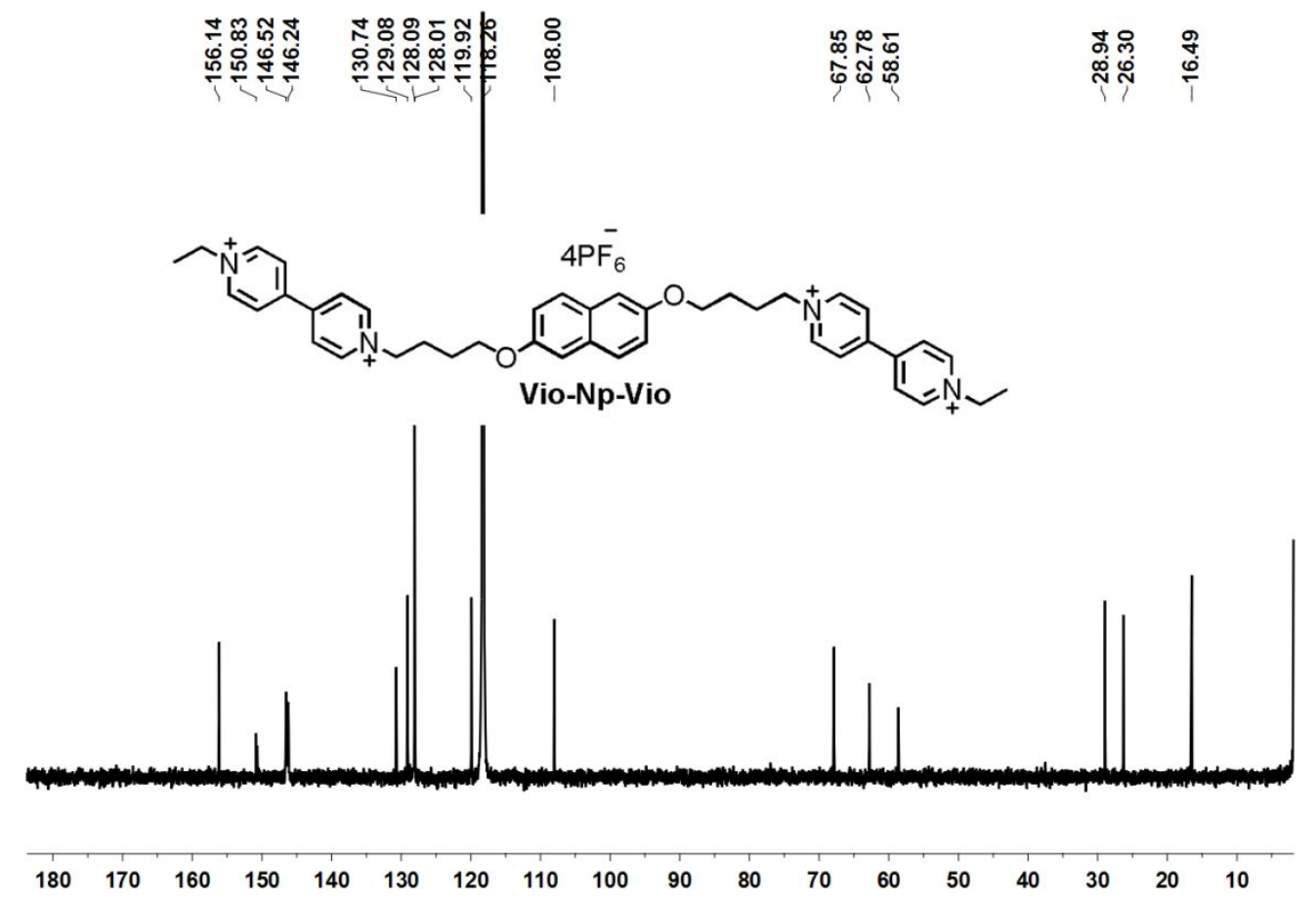

Figure S39. ${ }^{13} \mathrm{C}$ NMR spectrum of compoundVio-Np-Vio

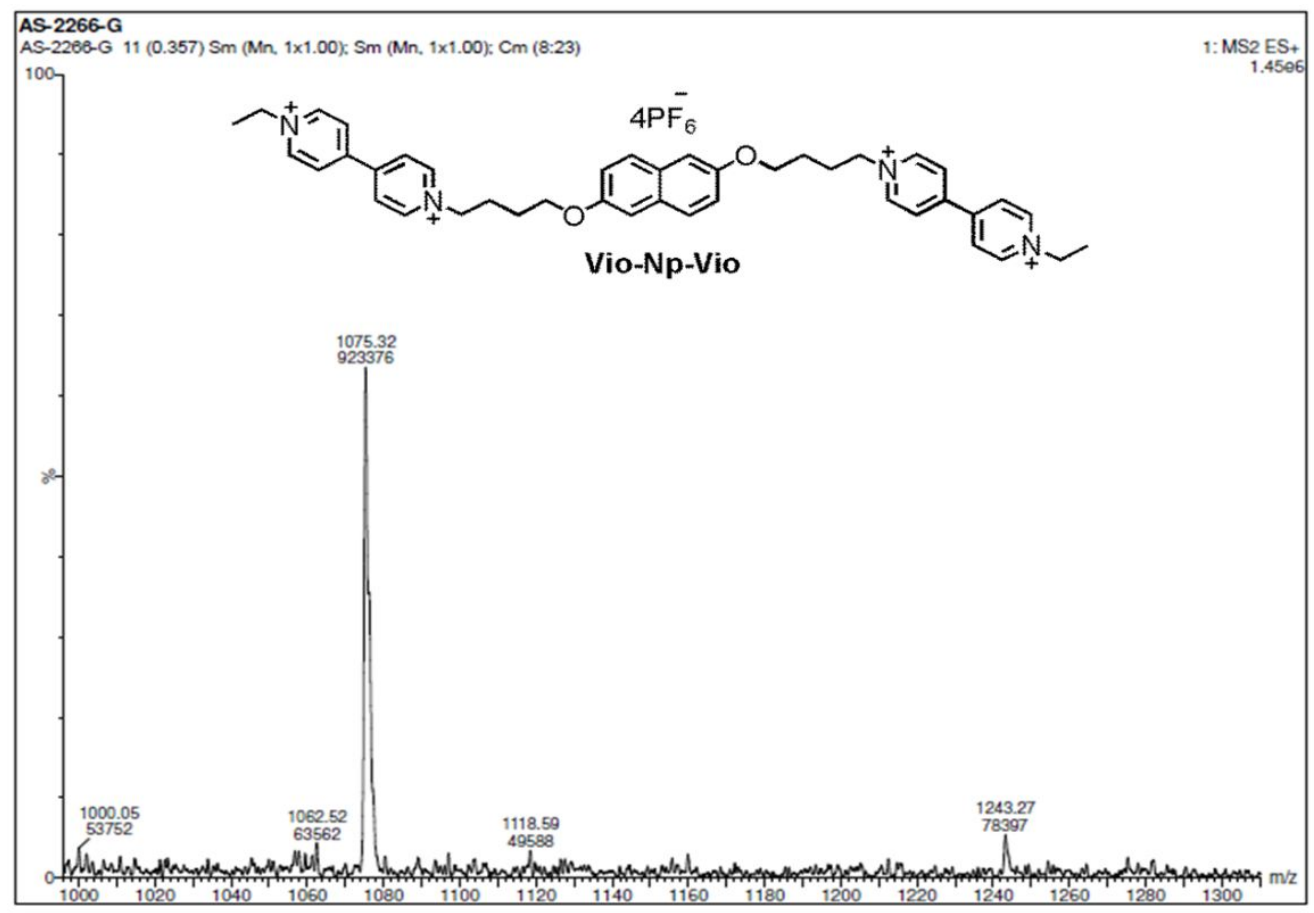

Figure S40. ESI-MS spectrum of compound Vio-Np-Vio in acetonitrile $\left((2 \mathrm{M}+\mathrm{Cu})^{+}, \mathrm{m} / \mathrm{z}\right.$ $=145)$. 


\section{References}

1. D. Zou, S. Andersson, R. Zhang, S. Sun, B. Åkermark and L. Sun, Chem. Commun., 2007, 4734-4736.

2. D. Xu, Y. Ma, Z. Jing, L. Han, B. Singh, J. Feng, X. Shen, F. Cao, P. Oleynikov, H. Sun, O. Terasaki and S. Che, Nat. Commun., 2014, 5, 4262.

3. K. Madasamy, V. M. Shanmugam, D. Velayutham and M. Kathiresan, Sci. Rep., 2018, 8, 1354. 